NBER WORKING PAPER SERIES

\author{
BUSINESS CYCLES AND \\ THE ASSET STRUCTURE OF \\ FOREIGN TRADE
}

Marianne Baxter

Mario J. Crucini

Working Paper No. 4975

\author{
NATIONAL BUREAU OF ECONOMIC RESEARCH \\ 1050 Massachusetts Avenue \\ Cambridge, MA 02138 \\ December 1994
}

We have received valuable comments on this paper from workshop participants at the International Monetary Fund, the 1992 NBER Summer Institute, Ohio State University, Simon Fraser University, University of British Columbia, University of Rochester, University of Virginia, and University of Washington. We are responsible for any remaining errors. Dave Backus generously provided us with the Solow residual time series used in section 3; Masao Ogaki provided us with his computer programs for unit root and cointegration tests, and aided us in their implementation. Neither of these individuals retains any culpability for the uses to which we put their material. The first draft of this paper was completed while Baxter was a visitor at the Institute for Empirical Macroeconomics; she is grateful for the support of the IEM and the National Science Foundation. This paper is part of NBER's research program in International Finance and Macroeconomics. Any opinions expressed are those of the authors and not those of the National Bureau of Economic Research.

(C) 1994 by Marianne Baxter and Mario J. Crucini. All rights reserved. Short sections of text, not to exceed two paragraphs, may be quoted without explicit permission provided that full credit, including (c) notice, is given to the source. 


\title{
BUSINESS CYCLES AND \\ THE ASSET STRUCTURE OF FOREIGN TRADE
}

\begin{abstract}
International financial market linkages are widely believed to be important for the international transmission of business cycles, since these govern the extent to which individuals can smooth consumption in the presence of country-specific shocks to income. This paper develops a two-country, general equilibrium model with restricted asset trade and provides a detailed analysis of the channels through which these financial linkages affect international business cycles. Our central finding is that the absence of complete financial integration may not be important if the shocks to national economies are of low persistence, or are transmitted rapidly across countries over time. However, if shocks are highly persistent or are not transmitted internationally, the extent of financial integration is central to the international transmission of business cycles.
\end{abstract}

Marianne Baxter

Department of Economics

University of Virginia

Rouss Hall, Room 118

Charlottesville, VA 22903

and NBER
Mario J. Crucini

Department of Economics

Ohio State University

410 Arps Hall

1945 North High Street

Columbus, OH 43210-1172 


\section{Introduction}

Economists have long understood that financial markets play a central role in the international propagation and transmission of business cycles. Morgenstern's (1959) book is a classic reference on this subject, but discussions of the link between financial markets and business cycles can be found in the earlier writings of Mitchell (1929), who attributed a positive and increasing correlation of international business cycles to the growth of international financial markets. The extent of international financial integration should be important for international business cycles, since an important function of financial markets is to permit individuals to smooth consumption in response to fluctuations in income. Thus the extent to which a country can trade on world financial markets will determine the extent to which its citizens can insure themselves against nation-specific components of business-cycle risk. The goal of the present paper is to provide a detailed analysis of the channels through which international financial linkages affect international business cycles.

Our framework is a two-country, single-good, general equilibrium model related to those used in the "open economy real business cycle" literature. This literature highlights the transmission of international business cycles in an equilibrium setting through the influences of interest rates and asset prices. ${ }^{1}$ However, this literature is often criticized for its treatment of international financial market linkages. That is: this literature assumes that individuals have access to complete international contingent-claims markets which permit them to pool all risks. A second strand of literature studies business cycles in small open economies. These studies typically restrict access to international risk-sharing in ways that seem, empirically, to be more reasonable than the assumption of complete markets. ${ }^{2}$ But these analyses are necessarily silent on the factors affecting world interest rates and asset prices.

This paper develops a two-country, general equilibrium model in which individuals have incomplete access to international risk-sharing. Using this model as our laboratory, we evaluate the importance of financial market linkages for the character of international business cycles, by comparing its predictions to the complete-markets model. Our main findings are as follows. First, we find that restricting asset trade to noncontingent bonds alone does not necessarily alter, in an important way, the predictions of the standard, complete markets model. If the international productivity process is trend stationary with substantial international "spillovers" of productivity shocks, the two models are essentially indistinguishable. If, however, productivity in each country follows a random walk without spillovers but with correlated innovations, restricting asset trade alters the predictions of the model along several important dimensions. In particular, under this parameterization, the complete markets

\footnotetext{
${ }^{1}$ See, for example, contributions by Backus, Kehoe, and Kydland (1992); Baxter and Crucini (1993); and Reynolds $(1992,1993)$.

${ }^{2}$ See, for example, the contributions of Cardia (1991), Correia, Neves, and Rebelo (1994), and Mendoza (1991).
} 
model predicts low cross-country output correlations and near-perfect consumption correlations; the bond economy conversely predicts high output correlations and low consumption correlations. This finding is important, since the complete markets model has been heavily criticized for its counterfactual prediction of near-perfect international consumption correlations for a wide range of parameterizations. With random walk shocks, restricting asset markets brings the consumption correlation down substantially.

Second, we find that the major differences in the macroeconomic response to shocks under the alternative asset structures are due almost entirely to differential wealth effects. In particular, we found strong differences across asset structures when productivity follows a random walk. In this case, under complete markets, individuals receiving a favorable productivity shock experience a negative wealth effect, because the optimal insurance character of equilibrium requires them to increase labor supply while transferring a large proportion of the additional output to residents of the other country. In the bond economy, however, individuals own all the risky claims to their country's output. Thus individuals receiving a favorable productivity shock experience a positive wealth effect, which induces them to increase consumption by more than in the complete markets economy and, more importantly, causes them to decrease labor input.

Although our primary goal was to understand the relationship between financial integration and business cycles, this analysis also contributes to the growing literature on "open economy real business cycles." Specifically, we discussed above that the model with restricted asset market linkages provides an explanation for the fact that, empirically, international consumption correlations are lower than international output correlations. Further, we find that the model with restricted asset markets can generate correlations between productivity and labor input that are much closer to those observed in the data, compared with those generated by a standard closedeconomy models driven by technology shocks alone. That is: restricted asset trade is another possible resolution of the so-called "Dunlop-Tarshis" observation, which is the low correlation of productivity and labor input observed in the data. ${ }^{3}$

Although the dominant source of differences across asset structures was found to lie in wealth effects, consumption and leisure are strongly affected in both asset structures by interest rate effects and wage effects. Thus the general equilibrium structure, in which interest rates and asset prices are determined endogenously, is important for understanding the way in which economies respond to exogenous shocks. This consideration is important even if the economy in question is "small" in the sense of producing a small share of world output.

Our work is related to that of Cole [1988), who studied the implications of financial structure for business cycles in a two-period model with production. More

${ }^{3}$ See Christiano and Eichenbaum (1992) for more discussion, and a different proposed resolution of the puzzle based on government spending shocks combined with important measurement error in labor input. 
recently, the relationship between asset markets and real activity has been studied by Conze, Lasry, and Sheinkman [1990), and Kollman (1990). They find, as we do, that restrictions on asset markets leads to lower international correlations of consumption. Constantinides and Duffie (1991) find that, when idiosyncratic shocks are purely permanent, there is no bond trade in equilibrium. However, in our model permanent shocks affect the marginal productivity of capital, so trade in bonds occurs even with unit-root shocks. Telmer (1991) studies an endowment economy with asset trade restricted to bonds only, and finds that this restriction has little effect on asset prices when idiosyncratic shocks are stationary. Heaton and Lucas (1994) use an endowment economy with restricted asset trade to study the effects of market incompleteness on asset returns.

The paper is structured as follows. Section 2 describes the model economy and discusses aspects of the solution procedure that differ from the prior, complete markets analyses. Section 3 begins with a review of previous work on estimating the stochastic process for productivity, and presents some new results. Taken together, these results suggest that productivity shocks are highly persistent, are correlated across countries, and may contain unit roots. Therefore, we compared the predictions of the complete markets model to the predictions of the model with restricted asset markets under two alternative parameterizations of the productivity process: (i) a trend-stationary process with innovations that are correlated across countries and with international transmission of shocks; and (ii) a difference-stationary process without transmission but with correlated innovations. We find that the empirical implications of the models are very sensitive to the specification of the stochastic process for productivity. If productivity follows a trend-stationary process with highly persistent shocks and international transmission, the business cycle implications of the incomplete markets economy are very similar to those of the complete markets economy. However, if productivity follows a random walk without transmission, the implications of the alternative models are quite different. Section 4 explores the economic forces behind the differential response under alternative asset structures by studying the dynamic response to a productivity shock originating in one country. Using King's (1990) method for decomposing consumption and labor responses into wealth and substitution effects, we find that differences across asset structures-when they exist-can be traced primarily to differential wealth effects. Section 5 briefly summarizes the paper's main results and discusses avenues for future research.

\section{The Model}

The basic structure of this model, in terms of preferences and technology, is identical to the structure in Baxter and Crucini (1993). The main difference arising from restrictions on asset trade appears in the flow constraints (budget constraints), which differ across the two models. Foreign country variables are denoted by stars, and all variables are in national per capita terms. 
Preferences: Individuals consume two goods: a produced consumption good, $C$, and leisure, $L$. They maximize expected lifetime utility, given by:

$$
\begin{gathered}
E_{0} \sum_{t=0}^{\infty} \beta^{t} \frac{1}{1-\sigma}\left[C_{t}^{\theta} L_{t}^{1-\theta}\right]^{1-\sigma} \text { home country; } \\
E_{0} \sum_{t=0}^{\infty} \beta^{t} \frac{1}{1-\sigma}\left[\left(C_{t}^{*}\right)^{\theta}\left(L_{t}^{*}\right)^{1-\theta}\right]^{1-\sigma}, \text { foreign country. }
\end{gathered}
$$

In each country, individuals are subject to the constraint that hours worked in the marketplace plus hours of leisure cannot exceed the time endowment, normalized to one unit:

$$
\begin{aligned}
1-L_{t}-N_{t} & \geq 0, \text { home country; } \\
1-L_{t}^{*}-N_{t}^{*} & \geq 0, \text { foreign country. }
\end{aligned}
$$

Technology: Production functions exhibit constant returns to scale, and production of the single final good requires the input of both labor and capital. Capital used in production in a specific country is not necessarily owned by residents of that country; thus, $K_{t}$ represents capital in place in the home country, not necessarily capital owned by residents of the home country. Labor is internationally immobile. Letting $N_{t}$ denote labor employed in the home country, these production functions are given by:

$$
\begin{gathered}
Y_{t}=A_{t} K_{t}^{1-\alpha}\left(X_{t} N_{t}\right)^{\alpha}, \text { home country; } \\
Y_{t}^{*}=A_{t}^{*}\left(K_{t}^{*}\right)^{1-\alpha *}\left(X_{t}^{*} N_{t}^{*}\right)^{\alpha *}, \text { foreign country. }
\end{gathered}
$$

In these production functions, the variables $X_{t}$ and $X_{t}^{*}$ represent the level of purely labor-augmenting technical change in the home and foreign countries, respectively, and each grows at a common, constant gross rate: $\gamma=X_{t+1} / X_{t}=X_{t+1}^{*} / X_{t}^{*}$. The variables $A_{t}$ and $A_{t}^{*}$ represent the stochastic component of the productivity variable, and are assumed to follow a vector Markov process.

New capital goods are internationally mobile, and all investment is subject to costs of adjustment governed by the function $\phi(I / K)$, with $\phi>0, \phi^{\prime}>0, \phi^{\prime \prime}<0$, as in Hayashi (1982). Capital accumulates over time according to:

$$
\begin{gathered}
K_{t+1}=(1-\delta) K_{t}+\phi\left(I_{t} / K_{t}\right) K_{t}, \text { home country; } \\
K_{t+1}^{*}=(1-\delta) K_{t}^{*}+\phi\left(I_{t}^{*} / K_{t}^{*}\right) K_{t}^{*}, \text { foreign country. }
\end{gathered}
$$

Capital adjustment costs have been incorporated to slow the response of investment to location-specific shocks. Because there is a single good produced in two 
different countries, capital owners have a strong incentive to locate new investment in the more-productive location (so long as productivity shocks are persistent). Without some friction in the capital adjustment process, the model would display excessive volatility of investment.

\subsection{Complete markets}

The first model that we shall study is also, in many ways, the simplest. There are two countries in the world, and individuals in the two countries are free to trade any state-contingent asset they wish. Thus, in equilibrium, individuals will bear no idiosyncratic risk. Since the consumption/investment good is internationally mobile, there is a single world resource constraint for this good. Letting $\pi$ denote the fraction of the world population residing in the home country, the world resource constraint is:

$$
\pi\left[Y_{t}-C_{t}-I_{t}\right]+(1-\pi)\left[Y_{t}^{*}-C_{t}^{*}-I_{t}^{*}\right] \geq 0 .
$$

The equilibrium of this economy consists of a set of functions describing the behavior of endogenous variables such as consumption, saving, investment, etc., as functions of the exogenous shocks to the model (i.e., the productivity shocks). Before solving our model, we transform it to remove deterministic trend components; this is accomplished by dividing all home country variables by $X_{t}$, and all foreign country variables by $X_{t}^{*}$. Lowercase letters are used below to denote transformed variables. Note that labor and leisure cannot have deterministic trends; otherwise, the "time constraints" would eventually be violated. These variables continue to be represented by uppercase letters. Finally, the common rate of time preference for all individuals in the transformed world economy is $\tilde{\beta} \equiv \beta \gamma^{\theta(1-\sigma)}$. The Appendix discusses the details of the approach that we use to solve for this model's competitive equilibrium.

\subsection{General equilibrium in a two-country world with re- stricted asset markets}

The model differs from the general equilibrium economy described in section 2.1 above in that this world economy is restricted to trade only goods and non-contingent real debt. For simplicity, but without loss of generality, the single debt instrument is a one-period discount bond. We let $r_{t}$ denote the world rate of return on risk-free securities, and let $P_{t}^{B} \equiv\left(1+r_{t}\right)^{-1}$ denote the price per unit of one-period discount bonds purchased in period $t . B_{t+1}$ denotes the quantity of bonds purchased in period $t$ (maturing in $t+1$ ). Following our earlier convention of letting lowercase letters refer to the transformed economy, we let $b_{t} \equiv B_{t} / X_{t}$ denote the value of bonds in the transformed economy. Then the flow budget constraint for the home country in period $t$ is: 


$$
\gamma P_{t}^{B} b_{t+1}+c_{t}+i_{t} \leq y_{t}+b_{t} .
$$

and for the foreign country is:

$$
\gamma P_{t}^{B} b_{t+1}^{*}+c_{t}^{*}+i_{t}^{*} \leq y_{t}^{*}+b_{t}^{*} .
$$

As before, let $\pi$ be the fraction of world population residing in the home country. Then, since bonds are in zero net supply at the world level, bond market clearing requires that:

$$
\pi b_{t}+(1-\pi) b_{t}^{*}=0 .
$$

Finally, the transversality conditions for the incomplete-markets economy are:

$$
\begin{aligned}
& \lim _{t \rightarrow \infty} \tilde{\beta}^{t} p_{t} b_{t+1}=0, \\
& \lim _{t \rightarrow \infty} \tilde{\beta}^{t} p_{t}^{*} b_{t+1}^{*}=0,
\end{aligned}
$$

where $p_{t}, p_{t}^{*}$ are the multipliers associated with the constraints (9) and (10).

By permitting asset accumulation, we have introduced a new parameter: the steady state level of assets relative to output. In closed economies and in multicountry models with fully pooled equilibria, each country's holdings of assets which are in zero net supply must be constant along any equilibrium path. In general, however, whenever there are multiple countries and incomplete risk pooling, the steady state level of asset holdings will not be invariant to shocks to the world economy. We set $\theta_{b}=b / y=0$ so that per capita wealth is equal across countries in the deterministic steady state.

The Appendix describes in detail how we solve for competitive equilibrium in this model. The key insight is that the shifting wealth distribution associated with market incompleteness can be appropriately accounted for by adding one country's current bond holdings to the model's state vector. That is: the distribution of bond holdings across countries in the world is a sufficient statistic for the history of the economy in terms of determining current decisions by individuals. Thus models with market incompleteness can be analyzed using the methods developed for complete markets models with $J$ countries, with the modification that the state space must be expanded to include the bond holdings of $J-1$ of the countries.

\section{Implications for Business Cycles}

In this section we examine the implications for the character of international business cycles of restricting the portfolio of internationally tradable assets. We begin by reviewing the international stylized facts, and then discuss the calibration of our 
model. We turn next to the measurement and estimation of the productivity process. Whether asset markets are important depends importantly on the properties of the stochastic process for productivity. For this reason, this section also presents some new empirical evidence on international productivity.

\subsection{Open economy business cycles}

Table 2 presents summary business cycle statistics for eight OECD countries. To render the data stationary, all variables have been filtered with the Hodrick and Prescott (1980) filter. The central stylized facts of business cycles are similar across countries: (i) there is a tendency for consumption to be less volatile than output while investment is more volatile; (ii) output movements are highly persistent; and (iii) consumption and investment are both highly correlated with fluctuations in output. The lower panel of Table 2 shows that both outputs and consumptions have a tendency to covary positively across countries, but international consumption correlations tend to be lower than international output correlations. Finally, labor market data for the U.S. shows that (i) labor input is less volatile than output, as is average labor productivity; (ii) labor input is highly correlated with output, as is the average product of labor, and (iii) average labor productivity and the level of labor input are roughly uncorrelated. Labor market statistics for other countries are omitted since accurate measures of total labor input are not readily available.

\subsection{Calibration and model solution}

The world is assumed to comprise two equally-sized countries with identical preferences and technology. The parameters of preferences and technology are the same as in Baxter and Crucini (1993). That is: the coefficient of relative risk aversion is set at $\sigma=2$, which is in the range of many empirical estimates. Labor's share is $\alpha=.58$; as noted in King, Plosser, and Rebelo (1988), this is the average postwar value of labor share in GNP, excluding proprietor's income. The discount factor, $\beta$, is set so that the steady state annual real interest rate is $6.5 \%$; the average quarterly gross growth rate of the economy is $\gamma=1.004$, and the quarterly depreciation rate is $\delta=.025$. These parameter values were set so that the model's steady state matches the average postwar behavior of the U.S. economy. The business-cycle behavior of the model is insensitive to modest perturbations in these parameters; for a sensitivity analysis of the complete market models, see Baxter and Crucini (1993).

The adjustment cost function is specified as follows. Since we are interested in the near-steady-state dynamics of the model economy, we do not need to specify a particular functional form for adjustment costs. Rather, we need only specify the near-steady-state behavior of the adjustment cost function. That is: we must specify the level, slope, and curvature of this function at the steady state point. Thus we set $\phi^{\prime}$ so that the steady state value of Tobin's ' $q$ ' is one - that is: the model with adjustment 
costs has the same deterministic steady state as the model without adjustment costs. Further, the elasticity of the investment-capital ratio with respect to Tobin's ' $q$ ' is $\eta=-\left(\phi^{\prime} / \phi^{\prime \prime}\right) \div(i / k)=15$. Alterations in this elasticity primarily affect the volatility of investment, thus we have set this parameter so that the model generates realistic investment volatility.

It is well known that the system of equations that implicitly defines the equilibrium of the one-sector closed-economy model does not have an analytic solution, except in a small number of special cases. A variety of numerical methods have recently been developed for obtaining approximate solutions to a particular nonlinear equilibrium problem: see the summary paper by Taylor and Uhlig (1990) and the papers cited therein. One method which has been shown to work well for the closed-economy neoclassical model is log-linear approximation of the equilibrium decision rules that solve the Euler equations; see, for example, Dotsey and Mao (1992). The point around which the approximation is taken is the model's initial deterministic steady state. The resulting linear system is solved by application of standard linear systems theory, as described in King, Plosser, and Rebelo (1987). See their paper for more details on the solution method and its properties.

\subsection{Measuring productivity}

Following the work of Solow (1957), it has become commonplace to measure disembodied productivity ( $A_{t}$ and $A_{t}^{*}$, in our notation) as a residual from a Cobb-Douglas production function. In the notation of our model, the "Solow residuals" would be measured as:

$$
\begin{gathered}
\log \left(A_{t}\right) \equiv \log \left(y_{t}\right)-(1-\alpha) \log \left(k_{t}\right)-\alpha \log \left(N_{t}\right) \\
\log \left(A_{t}^{*}\right) \equiv \log \left(y_{t}^{*}\right)-\left(1-\alpha^{*}\right) \log \left(k_{t}^{*}\right)-\alpha^{*} \log \left(N_{t}^{*}\right)
\end{gathered}
$$

Measurement of the Solow residual therefore requires measures of output, capital input, labor input, and factor shares. For the United States, measures of all these variables are available, although there naturally is substantial disagreement concerning the accuracy of these measures. For other countries, in many cases, the necessary data are not readily available. Backus, Kehoe, and Kydland (1992) used output data and employment data to construct estimates of Solow residuals for the U.S., Canada, and an aggregate of six European countries. These measures omit the term involving capital input. Further, the mismeasurement of labor input by using employment in place of total hours worked is a potentially serious problem: Burdett and Wright (1989) show that for many European countries, more of the variance in total labor input is explained by hours variation than by employment variation. Despite the measurement problems, the Backus, et al. estimates provide a valuable starting point, and we begin by briefly reviewing their findings. 
Backus, Kehoe, and Kydland (1992) modeled the productivity shock process as the following vector-autoregressive process:

$$
\begin{aligned}
& \log A_{t} \\
& \log A_{t}^{*}
\end{aligned}=\left[\begin{array}{cc}
\rho & \nu \\
\rho^{*} & \nu^{*}
\end{array}\right]\left[\begin{array}{l}
\log A_{t-1} \\
\log A_{t-1}^{*}
\end{array}\right]+\left[\begin{array}{c}
\epsilon_{t} \\
\epsilon_{t}^{*}
\end{array}\right]
$$

with $E(\epsilon)=E(\epsilon *)=0$ and $E\left(\epsilon^{2}\right)=\sigma_{\epsilon}^{2}, E\left((\epsilon *)^{2}\right)=\sigma_{\epsilon *}^{2}$, and $E\left(\epsilon_{t}, \epsilon_{t}^{*}\right)=\psi$ for all $t$. Backus, Kehoe, and Kydland (1992) estimated eq. (14) for (i) the U.S. versus Canada, and (ii) the U.S. versus an aggregate of six European countries. Their estimates are given below; standard errors are in parentheses.

$$
\begin{aligned}
& \text { U.S.: } \quad\left[\begin{array}{c}
\log A_{t} \\
\\
\text { Canada: } \\
\log A_{t}^{*}
\end{array}\right]=\left[\begin{array}{cc}
0.989 & 0.131 \\
(0.060) & (0.052) \\
0.000 & 0.796 \\
(0.093) & (0.079)
\end{array}\right]\left[\begin{array}{c}
\log A_{t-1} \\
\log A_{t-1}^{*}
\end{array}\right]+\left[\begin{array}{c}
\epsilon_{t} \\
\epsilon_{t}^{*}
\end{array}\right] ; \rho\left(\epsilon_{t}, \epsilon_{t}^{*}\right)=0.434
\end{aligned}
$$

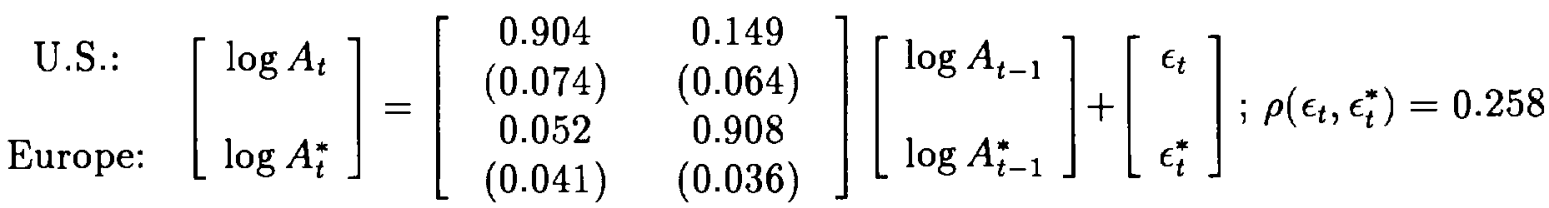

We see from these estimates that shocks to productivity are highly persistent, and that there is some evidence of transmission of shocks from one country to another $\left(\nu, \nu^{*}>0\right)$. Further, the innovations to productivity are positively correlated across countries. ${ }^{4}$

Because the Backus, et al. estimates indicate that shocks to the productivity process are highly persistent and that the transmission or "spillover" parameters are positive but carry large standard errors, we investigated the hypothesis that the Solow residuals follow a random walk without spillovers, but with possibly correlated innovations. ${ }^{5}$ Table 1, panel A reports the results of the $J(p, q)$ test for a unit root and zero transmission in each of the three Solow residual series generated by Backus, Kehoe, and Kydland (Canada, Europe, and the U.S.). In each case, we fail to reject the null hypothesis at conventional significance levels.

A natural next question is whether there is a cointegrating relationship between the Solow residual time series. Table 1 , Panel $B$ reports the results of tests for cointegration: there is evidence of cointegration between the U.S. and Canada, but the evidence for cointegration is weaker for the U.S. and Europe. Based on these results, we estimated a vector-error-correction model for the U.S. and Canada, and a standard VAR in first-differences for the U.S. and Europe; the results are in Table 1,

${ }^{4}$ See also a recent contribution by Reynolds (1993). Her findings show that, in many cases, the spillover parameters are not significantly different from zero.

${ }^{5}$ All test statistics used in this analysis are discussed in Park [1990]. 
panel $C$. There appears to be no significant international transmission of shocks, with the possible exception of transmission between the U.S. and Canada. Based on these estimates, we cannot reject the hypothesis that productivity in each country follows a random walk with drift, without transmission, but with innovations that are positively correlated across countries. In the remainder of the paper, we therefore examine the business cycle implications of alternative asset structures under two assumptions concerning the stochastic process for productivity: (i) Backus, Kehoe, and Kydland's "symmetrized parameterization," which is characterized by trend-stationary shocks with correlated innovations and substantial international transmission ("spillovers"); and (ii) a random walk process for productivity without spillovers, but with correlated innovations.

\subsection{Trend stationary productivity with spillovers}

We begin by comparing the cyclic behavior of the complete markets economy to that of the bond economy when the stochastic process for productivity is given by the Backus, et al. "symmetrized parameterization" of the relationship between U.S. and European productivity under which $\rho=\rho^{*}=0.906, \nu=\nu^{*}=0.088$, and $\psi=0.258$. Under this parameterization, innovations to productivity are positively correlated across countries $(\psi>0)$ and shocks that originate in one country "spill over" to the other country at the rate of $8.8 \%$ per quarter $(\nu=.088)$. We set the innovation variances equal to one. ${ }^{6}$

Table 3 compares the response of the complete markets economy to the economy which is restricted to financial trade in bonds alone when both economies are driven by the trend-stationary productivity shock with spillovers. The statistics reported in this table are the model's population moments for Hodrick-Prescott (1980) filtered time series. ${ }^{7}$ Surprisingly, the differences between the business cycle implications of these two (apparently) very dissimilar models are really quite minor. Compared with the complete markets economy, the bond economy displays similar volatility of output, consumption, investment, labor input, the wage rate, and the net export ratio. ${ }^{8}$ In the bond economy, however, bond holdings as a fraction of output are about three times as volatile as output. Bond holdings have zero variance in the complete

\footnotetext{
${ }^{6}$ Since our log-linear solution algorithm generates decision rules that display certainty equivalence, only the scale of volatility changes as we change the innovation variances. Relative volatilities, such as the standard deviation of consumption divided by the standard deviation of output, are invariant in this setup to the size of the shock variance.

${ }^{7}$ The population moments for the filtered time series are computed using the rational polynomial version of the Hodrick-Prescott filter applicable to an infinite sample of data, as discussed in King and Rebelo [1993]. Even though the incomplete markets model implies that there is a unit root component to each country's real quantity variables, the HP filter contains four differences in the numerator of the rational polynomial, so that population moments for the filtered series are welldefined.

${ }^{8}$ In our model, the wage rate equals the average product of labor.
} 
markets economy; a well-known characteristic of fully-pooled equilibria is that asset holdings need not fluctuate. In terms of persistence, the two models are essentially indistinguishable except, once again, for the behavior of bond holdings.

Turning to the contemporaneous correlation of macroeconomic aggregates with output, we see that the bond economy generally predicts higher correlations of most variables with same-country output, although the numerical differences are very small. The bond economy predicts higher international correlations of output, investment, and labor input, and smaller international correlations between consumption and wage rates. The within-country correlation between saving and investment is slightly lower in the bond economy compared with the complete markets economy. This might seem surprising, since one's intuition is that closing asset markets, thus forcing individuals to bear more country-specific risk, would act to increase within-country saving-investment correlations. However, this "basic saving measure" (defined as output minus consumption) need not be a good measure of true saving in an open economy, as discussed by Obstfeld (1986) and Stockman and Svensson (1987).

Finally, the asset structure is of minor importance for the predicted correlation between the wage rate and the level of labor input. The complete markets economy predicts a correlation of 0.66 , which is about the same as the predictions of the closedeconomy real business cycle model calibrated to U.S. data (e.g., the model in Baxter and King (1991) predicts a correlation of 0.65). Restricting asset trade to bonds alone has the effect of slightly increasing the predicted correlation, to a level of 0.69 . In the U.S. data, this correlation is -0.04 .

How do these models do overall in terms of generating empirically accurate predictions? As discussed by Backus, Kehoe, and Kydland (1992) and Baxter and Crucini (1993), the complete markets economy does reasonably well in matching the stylized facts concerning volatility and persistence of macro aggregates. Much more problematic are the complete markets model's implications for cross-country correlations of output, consumption, investment, and labor input. Specifically, this model has difficulty generating positive output comovement (and correspondingly positive comovement of investments and labor inputs across countries). Further, the model predicts a level of cross-country consumption correlation that is much too high relative to the data.

Because individuals are subject to idiosyncratic (nation-specific) risk in the bond economy, in equilibrium this economy will display nation-specific fluctuations in consumption. Thus we expect that the international correlation between consumptions should be lower in the bond economy, and it is-but not much lower. The complete markets economy predicts an international consumption correlation of 0.95 , while the bond economy predicts a correlation of 0.92 . (Table 2 shows that the empirical correlations range from 0.11 to 0.65 .)

Similarly, the absence of insurance against labor income risk in the bond economy is important for the cross-country correlation of labor inputs. In the complete markets economy, the response to a positive productivity shock in one country generates an 
increase in labor input in the productive country, and a tendency for a decline in labor input in the relatively unproductive country. Because of the optimal insurance character of the complete markets equilibrium, workers in the productive country agree to "share" some of the additional output generated by the increase in productivity and labor input, in exchange for similar "sharing" when the other country receives a positive productivity shock. In the bond economy, individuals can only smooth consumption across time (by buying or selling bonds); they cannot smooth consumption across different "states of nature" because of the absence of contingent securities. This reduces the tendency for labor input to decline in the temporarily unproductive location (we will discuss the details of these mechanisms further in Section 4). But again, while we see this effect in somewhat higher international correlations between output, investment, and labor input, the effect is not strong enough to make the bond economy a good description of the international data along these dimensions.

In summary, with trend-stationary shocks and substantial spillovers, we find that restricting international trade in financial assets to noncontingent bonds alone has very minor effects on the model's predictions for the business cycle behavior of the key macroeconomic aggregates. In particular, restricting asset markets helps only slightly in remedying the chief empirical failings of the one-sector international equilibrium business cycle model, which are (i) high international consumption correlations; (ii) negative international correlations of output, labor input, and investment; and (iii) a strong, positive correlation between labor input and real wages.

\subsection{Random-walk productivity without spillovers}

As shown in Section 3.1, we cannot reject the statistical hypothesis that the logs of total factor productivity follow random walk processes without spillovers but with correlated innovations. This section therefore examines the implications of this process for the behavior of the complete markets economy and the bond economy. Table 4 presents the two models' predictions for the central business cycle statistics, under the assumption that $\rho=\rho^{*}=1, \nu=\nu^{*}=0$ (as in Table 3, these are Hodrick-Prescott filtered population moments). All other parameters, including the contemporaneous correlation of the shocks and the innovation variances, are the same as in Table 3.

It is immediately evident from Table 4 that there are important differences between the complete markets economy and the bond economy. In contrast to the results for the trend-stationary-with-spillovers parameterization, reported in Table 3, market structure matters a great deal when shocks are permanent and there is no transmission. First, the levels of output volatility, investment volatility, and labor input are substantially higher in the complete markets economy, compared with the bond economy; in fact investment and labor input are about twice as volatile in the complete markets economy. Recall that one effect of the complete risk-pooling in the complete markets economy is a strong increase in labor input in response to positive productivity shocks. Because of the complementarity of labor input and capital in- 
put, the stronger labor response in the complete markets setting is accompanied by a stronger investment response and, consequently, a stronger output response.

The most striking differences between the models appear when we look at the international correlations of output and consumption. As noted above, a well-known failing of the complete markets model is its robust prediction of too high an international consumption correlation, combined with a too-low prediction for the international correlation of outputs. In section 3.2, we saw that the bond economy shares this flaw when shocks to total factor productivity are trend-stationary and subject to spillovers. When the shocks are purely permanent, as in Table 4 , the complete markets economy continues to exhibit this counterfactual pair of predictions; in fact, the predictions for output correlations are even worse (i.e., even more strongly negative). But when the bond economy is subject to purely permanent shocks, this model predicts a substantial, positive international output correlation (0.54) and a negative consumption correlation $(-0.28)$ ! (While this configuration of correlations is unusual in the data, Baxter and Crucini (1993) did find this pattern of positive output correlations and negative consumption correlations for four country pairs.)

With random walk productivity, the two asset structures also differ importantly in their implications for the cyclic behavior of labor input. The bond economy predicts a weak (0.19) contemporaneous correlation of labor with output compared to the prediction of 0.93 for the complete markets economy. However, despite the fact that asset market restrictions have increased output correlations to an empirically reasonable level, the bond economy continues to underpredict international comovement of labor input and investment. With the random walk specification, both asset structures predict a negative correlation between the net export ratio and output, which is characteristic of most OECD countries (although not the United States). Under this parameterization, the complete markets model continues to predict high saving-investment correlations but the bond economy does not. In fact, the predicted correlation of 0.04 in the bond economy is much lower than saving-investment correlations typically found in the data for this measure of saving. (As noted earlier, however, this "basic saving" measure may not be an accurate measure of true saving in the economy.) Finally, the complete markets model predicts a substantial positive correlation between productivity and labor input, while the bond economy generates a strongly negative correlation. In the data, these variables are roughly uncorrelated.

Figure 0 shows how cross-country consumption and output consumption correlations, as well as within-country productivity-labor correlations, depend on the persistence of the shock and market structure. The top panel has results for the complete markets economy; the bottom panel has results for the bond economy. With complete markets, increasing persistence of the shock process leads to lower cross-country output correlations. The productivity-labor correlation also decreases with increased persistence, but never approaches the approximately zero correlation observed in the data. Changing persistence has a negligible (positive) effect on cross-country consumption correlations. 
In the incomplete markets economy, by contrast, consumption correlations decrease dramatically as persistence rises, as does the correlation between productivity and labor input. At the same time, cross-country output correlations rise with increased persistence. The economic mechanisms behind these effects are explored in the next section.

\section{Dynamic Response to a Productivity Shock}

The preceding section explored the implications for the summary statistics of business cycles of alternative assumptions concerning (i) the stochastic process for productivity shocks and (ii) market structure. The chief findings of that section were that restricting financial trade to noncontingent bonds alone had minor effects on the business cycle statistics when productivity was assumed to follow a trend stationary process exhibiting high persistence with substantial international transmission of shocks. However, when productivity contained a unit root, the restrictions on asset trade had important effects.

In order to explore the economic mechanisms behind these differential responses, this section studies the impulse responses of the alternative models when driven by the trend-stationary process of section 3.2 versus random walk shocks, as in section 3.3. Throughout, we study the response of the world economy to a $1 \%$ increase in total factor productivity which originates in the home country: $\hat{A}_{t}=0.01$.

\subsection{Random walk productivity}

In many ways the responses to purely permanent shocks are easier to understand, so we start with this case. Figure 1 plots the responses of aggregate quantity variables in the two countries, and Figure 2 plots the responses of real wages, real interest rates, and bond holdings. In both figures, stars denote the response of the bond economy, and open circles denote the response of the complete markets economy.

Figure 1 shows that, under both asset structures, home country output, consumption, and investment increase in response to the shock, while foreign country investment falls. However, labor market behavior across countries is sensitive to the asset structure, as is the cross-country behavior of consumption and output. First, under complete markets, labor input increases in the home country and falls in the foreign country; the reverse is true in the bond economy. Second, under complete markets, consumptions move together across countries while outputs move in opposite directions. In the bond economy, by contrast, consumptions move in opposite directions while output rises in both countries (at least for the first few periods).

Figure 2 shows that the real interest rate implications of the shock are virtually identical under the two asset structures; and that the positive productivity shock causes the home country wage rate to rise under both structures, reflecting the positive effect of the shock on labor productivity. However, the foreign country wage rate rises 
on impact in the complete markets economy but falls in the bond economy, mirroring the labor responses. Finally, with asset trade restricted to bonds alone, the foreign country accumulates bonds in response to the productivity shock in the home country, (there is no change in asset holdings in the complete markets economy). We have already seen that, in the bond economy, the foreign country responds by decreasing consumption and increasing labor input; thus they must be accumulating bonds over time. When adjustment to the shock is complete, the foreign country will work less and consume less than in the pre-shock steady state; however, a higher share of this consumption will be financed by the interest generated by the increased stock of debt accumulated over the transition path.

Figures 1 and 2 illustrate that the within-country and cross-country responses of consumption and labor are sensitive to the asset structure. In order to gain additional insight into the reasons why consumption and labor responses differ across asset structures, we employ King's (1990) "Hicksian" method for decomposing the consumption and labor supply responses into (i) a wealth effect, (ii) a real interest rate effect, and (iii) a wage effect. The wealth effect is computed as follows. First, compute the discounted present value of the change in utility caused by the altered time path of consumption and leisure (in response to the shock). Next, compute the constant consumption and leisure profiles that yield the same change in utility, using initial steady-state wages and interest rates. The real interest rate effect is that part of the response due to alterations in the interest rate alone, holding fixed wealth and wage rates at their initial steady state levels; the wage effect is computed in a similar fashion. These effects are plotted in Figure 3.

Beginning with the wealth effect on home country consumption, we find that the positive productivity shock has a positive wealth effect in the bond economy, but has a negative wealth effect under complete markets. The positive wealth shock in the bond economy is easy to understand - the positive productivity shock means that more output can be obtained using the same level of inputs. In the bond economy, these inputs are completely domestically-owned. Because individuals value both consumption and leisure, the natural response to a positive wealth shock (holding fixed all prices) is to consume more and work less; we see that the wealth effect on labor input is in fact negative in the bond economy (Figure 3-B).

Why is the home country wealth effect on consumption negative under complete markets? Recall that, under complete markets, the response to a location-specific positive productivity shock is for individuals living in the productive location to increase labor supply, taking advantage of the increase in productivity, while transferring some of the proceeds of the increased labor input to individuals living in less productive locations. Although home country consumption rises in response to the shock, home country leisure falls so much that home country discounted utility actually falls in response to the shock. Thus, the home country suffers a negative wealth effect.

In addition to the wealth effect, the productivity shock also induces substitution effects associated with (i) alterations in the time profile of real interest rates (the 
intertemporal price of consumption), and (ii) alterations in the time profile for the real wage rate. Since the real interest rate response is virtually identical under the two asset structures (see Figure 2), the substitution effect stemming from this channel is also virtually the same across the two cases. The substitution effect on home consumption arising from the increase in the wage profile is positive and similar in both cases, reflecting the fact that wages rise in response to the shock under both asset structures. Thus in the home country, the differential consumption response under the alternative asset structures is almost entirely due to differences in the size of the wealth effect.

Similar arguments explain the responses of home country labor supply (Figure 3-B). Under complete markets, the wealth effect on labor is positive; i.e., the negative wealth effect induces an increase in labor input. With financial trade restricted to bonds alone, the productivity shock implies a positive wealth shock, thus labor input falls. As with home country consumption, the discount rate effects are nearly identical across the two market structures: the increase in current real interest rates (an increase in the price of current leisure, relative to future leisure) leads to an increase in labor supply from this channel. The wage effect on labor input is positive in the bond economy, but negative in the complete markets economy. As with the consumption response, the biggest difference between the labor response across asset structures lies in the wealth effects. Because the wealth effects are of different sign under the alternative market structures, we find that labor input rises on impact in the complete markets setting, but falls on impact in the bond economy.

In the foreign country it is also the case that the dominant differences across the asset structures lie in the wealth effects. Because foreign country residents do not own productive factors located in the home country, and because there is no international transmission of the productivity shock, there is a zero wealth effect of the shock on consumption and on labor supply. Under complete markets, however, there is a positive wealth effect on consumption and a negative wealth effect on labor supply. With optimal labor insurance, the efficient arrangement calls for the lessproductive country to "take a paid vacation," working less and consuming more. Under complete markets, the strength of the wealth effect in depressing labor input is sufficient to counteract positive substitution effects from the increase in the real interest rate and the increase in the real wage rate. Thus, on impact, foreign labor input rises in response to the shock in the bond economy, but falls in the complete markets economy.

Finally, in this case the incomplete markets model generates the interesting prediction that cross-country output correlations exceed the cross-country correlation of productivity. The Hicksian decompositions help us understand this result, as follows. If we write out the production functions as

$$
\begin{gathered}
\log y_{t}=\log A_{t}+(1-\alpha) \log k_{t}+\alpha \log N_{t} \\
\log y_{t}^{*}=\log A_{t}^{*}+(1-\alpha) \log k_{t}^{*}+\alpha \log N_{t}^{*},
\end{gathered}
$$


then the correlation between $y_{t}$ and $y_{t}^{*}$ depends on the cross-correlations of all the variables in (15) and (16). In particular, negative cross-country correlations of labor input and capital would tend to make outputs less correlated than the Solow residuals. In the bond economy with random walk productivity, however, the output correlations exceed the productivity correlations because there is a positive correlation between the home country productivity shock and foreign labor input. When there is a positive domestic productivity shock, foreign labor input rises due to the interest rate effect (the wealth effect is zero, and the wage effect is slightly negative); these effects can be seen in Figures 1 and 3. The negative comovement between labor inputs arises because the increase in domestic productivity causes an initial decline in domestic labor input: here, the wealth effect temporarily outweighs the combined influences of the wage and interest rate effects.

\subsection{Trend-stationary shocks with spillovers}

Figures 4-6 plot the dynamic response to an innovation in home country productivity when productivity follows the trend-stationary process with spillovers specified in Section 3. We have already seen, in Table 3, that the summary statistics of business cycles are largely invariant to the asset structure under this parameterization of the productivity process. The dynamic responses detailed in Figures 4-6 give a similar impression: the responses of the quantity variables (Figure 4) and prices and interest rates (Figure 5) show very similar responses under the alternative asset structures. The only significant difference is that, in the bond economy, assets are decumulated in the foreign country in response to the home country productivity shock, whereas there is no change in asset holdings in the complete markets economy.

The Hicksian decompositions of the consumption and labor responses plotted in Figure 6 confirm the general impression that, with the trend-stationary process, there is little practical difference between the two asset structures. Recall that, with random walk productivity shocks, the primary difference across asset structures was due to differential wealth effects. In Figure 6, we see that the wealth effects on the two countries of the productivity shock are first of all small, and second, are virtually indistinguishable across the two asset structures. The wealth effect of a temporary shock will always be smaller than the wealth effect of a permanent shock of the same size, so that this in itself is not surprising. The fact that the wealth effects are almost identical across asset structures is more surprising, and this is largely due to the fact that the productivity shock is transmitted across countries over time via the "spillover" parameter, $\nu$. In fact, $8.8 \%$ of the shock is transmitted each quarter, and apparently this is rapid enough so that the wealth effects of the shock are nearly identical across countries even when asset trade is restricted to bonds alone (the wealth effect is identical across countries under complete markets). As before, the real interest rate effects are virtually identical across countries and across asset structures. 
Figure 6-B is useful in understanding the forces behind negative international comovement of labor input under this parameterization. Although the wealth effects and real interest rate effects of the shocks are approximately the same across countries, the wage effects are quite different. The wage effect on home country labor is positive, reflecting the higher productivity due to the shock itself, combined with a rapid run-up in investment (see Figure 4). In the foreign country, there is no immediate effect on productivity, although individuals in that country realize that productivity will increase in the future due to the "spillovers." That is, labor productivity in the foreign country is low, on impact, compared with its expected future value. Intertemporal substitution considerations mean that foreign country residents are induced to increase current leisure with the expectation of lower future leisure when the spillover effect brings increased productivity to the foreign country.

Once we understand the importance of the international transmission of the shock (the "spillover") for the wealth effects on labor and consumption, it is easy to understand why foreign country residents decumulate bonds in response to the shock. As noted above, these permanent-income consumers know that the favorable shock will be coming to their country in a few quarters-rapidly enough that the positive wealth effect is nearly as large as in the originating economy. But on impact, productivity in the foreign country is low relative to its expected future level. Thus individuals respond on impact to the positive wealth shock by decreasing current labor supply and increasing current consumption, financing part of current consumption from the proceeds of bond sales.

In summary, we find that with trend-stationary shocks and spillovers, the absence of risk-sharing arrangements stemming from asset market restrictions is not important for the character of international business cycles. With this parameterization of the productivity shock process, nearly all of the fluctuations in productivity are common across countries, i.e., there is little scope for risk-sharing in the first place, although there is a role for intertemporal trade since productivity arrives in the non-originating country with a lag. Since a real discount bond is the ideal instrument for undertaking intertemporal trade, the restriction of asset markets to bonds alone has little effect on equilibrium outcomes.

\section{Conclusions}

This paper has explored the importance of financial market linkages for the character of international business cycles. We have found that restrictions on asset trade may be important for business cycles, but that this result is sensitive to the stochastic process for productivity. In particular, restrictions on asset trade are more important (i) the more persistent is the shock; and (ii) the smaller are international spillovers of productivity shocks. When there are important differences across asset structures, these can be traced to important differences in wealth effects. 
This paper also contributes to the technical literature on solving dynamic models by providing an example of how Euler equation methods can be extended in a straightforward fashion to the study of suboptimal dynamic economies. In particular, this paper illustrates how one can compute equilibrium in models in which departures from optimality arise due to constraints on individuals' opportunities for risk-pooling, without suffering a significant increase in conceptual or computational complexity. Because the equilibrium behavior of dynamic models can always be characterized as the solution to a system of Euler equations (augmented by market clearing conditions and equilibrium "consistency conditions"), the same approach can be used to study other models in which departures from optimality arise for a number of possible reasons, such as market incompleteness, imperfect information, or departures from competitive equilibrium due to monopolistic behavior.

\section{A Appendix}

This appendix discusses the procedures that we use to solve the models described in this paper. We begin by discussing the complete-markets model, and then turn to models with restrictions on asset trade. Throughout, the notation is the same as described in section 3 .

\section{A.1 Complete markets}

Competitive equilibrium in the complete markets economy is also Pareto optimal, thus this equilibrium can be found by carrying out a standard Lagrangian problem, as specified below:

$$
\begin{gathered}
\max \mathcal{L}=E_{0} \sum_{t=0}^{\infty} \tilde{\beta}^{t}\left\{\left[\pi u\left(c_{t}, L_{t}\right)+(1-\pi) u\left(c_{t}^{*}, L_{t}^{*}\right)\right]\right. \\
+\pi w_{t}\left(1-L_{t}-N_{t}\right)+(1-\pi) w_{t}^{*}\left(1-L_{t}^{*}-N_{t}^{*}\right) \\
+\pi \lambda_{t}\left[(1-\delta) k_{t}-\left(\gamma k_{t+1}-\phi\left(i_{t} / k_{t}\right) k_{t}\right)\right] \\
+(1-\pi) \lambda_{t}^{*}\left[(1-\delta) k_{t}^{*}-\left(\gamma k_{t+1}^{*}-\phi\left(i_{t}^{*} / k_{t}^{*}\right) k_{t}^{*}\right)\right] \\
\left.+p_{t}\left[\pi\left(A_{t} F\left(k_{t}, N_{t}\right)-c_{t}-i_{t}\right)+(1-\pi)\left(A_{t}^{*} F\left(k_{t}^{*}, N_{t}^{*}\right)-c_{t}^{*}-i_{t}^{*}\right)\right]\right\}
\end{gathered}
$$

The multipliers on the constraints in the Lagrangian have the following natural interpretations as (utility-denominated) shadow prices:

$w_{t}, w_{t}^{*}:$ wage rate

$\lambda_{t}, \lambda_{t}^{*}$ : price of existing capital 
$p_{t}$ : price of the final good (price of new capital).

The competitive equilibrium for this economy is found by solving the system of firstorder necessary conditions plus "consistency conditions" arising from this Lagrangian problem. The competitive equilibrium for this particular economy is Pareto optimal, but this approach works more generally for non-optimal competitive equilibria; see Baxter (1991).

Letting $D$ to denote the total derivative of a function of a single variable, and letting $D_{j}$ denote the partial derivative of a function with respect to its $j^{\text {th }}$ argument, the first-order necessary conditions for this Lagrangian problem are:

$$
\begin{gathered}
c_{t}: D_{1} u\left(c_{t}, L_{t}\right)-p_{t}=0 \\
L_{t}: \quad D_{2} u\left(c_{t}, L_{t}\right)-w_{t}=0 \\
N_{t}: \quad p_{t} A_{t} D_{2} F\left(k_{t}, N_{t}\right)-w_{t}=0 \\
i_{t}: \quad \lambda_{t} D \phi\left(i_{t} / k_{t}\right)-p_{t}=0 \\
k_{t+1}: E_{t} \mu\left(i_{t+1} / k_{t+1}\right) \tilde{\beta} \lambda_{t+1}+\tilde{\beta} E_{t} A_{t+1} D_{1} F\left(k_{t+1}, N_{t+1}\right)-\gamma \lambda_{t}=0 \\
w_{t}: 1-L_{t}-N_{t}=0 \\
\lambda_{t}: \quad k_{t+1}=(1-\delta) k_{t}+\phi\left(i_{t} / k_{t}\right) k_{t} \\
p_{t}: \quad \pi\left[y_{t}-c_{t}-i_{t}\right]+(1-\pi)\left[y_{t}^{*}-c_{t}^{*}-i_{t}^{*}\right]=0 .
\end{gathered}
$$

for all $t \geq 0$, where $\mu(z) \equiv[\phi(z)-z D \phi(z)+(1-\delta)]$. There are foreign-country analogues to eqs. (17)-(23), and a transversality condition for capital in each country.

We solve the model by taking a log-linear approximation to the model's initial deterministic steady state. The resulting linear system is solved by application of standard linear systems theory, as described in King, Plosser, and Rebelo (1987). The planner weights are implicit in the steady state shares of world output consumed by residents of each country; we set these shares as part of the calibration exercise. As shown be Rebelo (1987) and discussed in detail in King, Plosser, and Rebelo $(1988 \mathrm{~b})$ it is not necessary to solve for the planner weights when solving the model by log-linear approximation, since the weights are absent from the linearized Euler equations. 


\section{A.2 A partial equilibrium model of a small open economy}

This sub-section describes a model of an open economy that is assumed to be too small to affect the world interest rate. This is a partial equilibrium model because the representative consumer in the small open economy optimizes in the face of an exogenous process for the world interest rate. Solving the small open economy model is a useful first step toward constructing a general equilibrium model with restricted asset trade. The flow budget constraint, or asset accumulation equation, for the small open economy is:

$$
\gamma P_{t}^{B} b_{t+1}+c_{t}+i_{t} \leq y_{t}+b_{t} .
$$

To solve the small open economy model, we specify the following Lagrangian problem and then solve the resulting system of first-order conditions:

$$
\begin{gathered}
\max \mathcal{L}=E_{0} \sum_{t=0}^{\infty} \tilde{\beta}^{t}\left\{u\left(c_{t}, L_{t}\right)\right. \\
+w_{t}\left(1-L_{t}-N_{t}\right) \\
+\lambda_{t}\left[(1-\delta) k_{t}-\left(\gamma k_{t+1}-\phi\left(i_{t} / k_{t}\right) k_{t}\right)\right] \\
+p_{t}\left(y_{t}+b_{t}-\gamma P_{t}^{B} b_{t+1}-c_{t}-i_{t}\right) .
\end{gathered}
$$

The first-order necessary conditions obtained by maximizing the Lagrangian with respect to $c_{t}, L_{t}, N_{t}, i_{t}, k_{t+1}, w_{t}$, and $\lambda_{t}$ are exactly the same as the corresponding efficiency conditions for the complete-markets economy described above, together with the transversality conditions for debt holdings (eqs. (12) and (13)). There are two first-order conditions that are different: these are the efficiency conditions for $b_{t+1}$ and for $p_{t}$ (i.e., the flow budget constraint) which are as follows:

$$
\begin{gathered}
\left(b_{t+1}\right): \tilde{\beta} E_{t} p_{t+1}-\gamma p_{t} P_{t}^{B}=0 \\
\left(p_{t}\right): \quad b_{t}+A_{t} F\left(k_{t}, N_{t}\right)-c_{t}-i_{t}-P_{t}^{B} \gamma b_{t+1}=0
\end{gathered}
$$

The steady state real interest rate is determined by equation $(26): \gamma P^{B}=\tilde{\beta} \cdot{ }^{9}$ The remaining first-order conditions determine the evolution of all endogenous variables as functions of the controlled states $\left(b_{t}, k_{t}\right)$; the corresponding costates $\left(p_{t}, \lambda_{t}\right)$; and the exogenous variables $\left(A_{t}, P_{t}^{B}\right)$. As before, the model can be linearized and solved using the procedure outlined in King, Plosser, and Rebelo (1987).

\footnotetext{
${ }^{9}$ Recall that we assumed that $\tilde{\beta}$ is the same for all countries in the world, so that (26) holds for each country, and $R \gamma=\tilde{\beta}$ is also a world general equilibrium condition. This requirement also guarantees that no country grows arbitrarily wealthy over time in the deterministic version of the model.
} 


\section{A.3 General equilibrium with restricted asset markets}

Next, we consider a two-country world in which each country can trade a noncontingent real bond with residents of the other country. That is: the representative individual in each country faces the same problem as the individual described above in the small open economy. The only difference is that, in general equilibrium, the interest rate process is not exogenous. Rather, the interest rate adjusts to clear the bond market. In particular, bond-market clearing requires that:

$$
\pi b_{t}+(1-\pi) b_{t}^{*}=0 .
$$

since bonds are in zero net supply in the world economy.

Combining equation (28) with aggregate financial asset accumulation equation

$$
\pi P_{t}^{B} b_{t+1}+(1-\pi) P_{t}^{B} b_{t}^{*} \geq \pi\left[b_{t}+y_{t}-c_{t}-i_{t}\right]+(1-\pi)\left[b_{t}^{*}+y_{t}^{*}-c_{t}^{*}-i_{t}^{*}\right]
$$

implies goods-market clearing (due to Walras' Law)

$$
\pi\left(A_{t} F\left(k_{t}, N_{t}\right)-i_{t}-c_{t}\right)+(1-\pi)\left(A_{t}^{*} F\left(k_{t}^{*}, N_{t}^{*}\right)-c_{t}^{*}-i_{t}^{*}\right) \geq 0 .
$$

The first-order necessary conditions for the representative individuals' problem are given by eqs. (17)-(23) (with foreign-country analogues), together with the following:

$$
\begin{gathered}
\left(b_{t+1}\right): \tilde{\beta} E_{t} p_{t+1}-\gamma p_{t} P_{t}^{B}=0 \\
\left(b_{t+1}^{*}\right): \tilde{\beta} E_{t} p_{t+1}^{*}-\gamma p_{t}^{*} P_{t}^{B}=0 \\
p_{t}: \quad b_{t}+A_{t} F\left(k_{t}, N_{t}\right)-c_{t}-i_{t}-P_{t}^{B} \gamma b_{t+1}=0 . \\
p_{t}^{*}: \quad b_{t}^{*}+A_{t}^{*} F\left(k_{t}^{*}, N_{t}^{*}\right)-c_{t}^{*}-i_{t}^{*}-P_{t}^{B} \gamma b_{t+1}^{*}=0 .
\end{gathered}
$$

In world general equilibrium, the interest rate process implicit in $P_{t}^{B}$ is endogenously determined: from (31) and (32), we have $P_{t}^{B}=\widetilde{\beta} E_{t}\left(p_{t+1} / \gamma p_{t}\right)=\widetilde{\beta} E_{t}\left(p_{t+1}^{*} / p_{t}^{*}\right)$

The key issue is how to compute the world general equilibrium. The procedure we use is as follows. First, we drop one of the asset accumulation equations (i.e., one of eqs. (33) and (34)) since eq. (28) implies that, in a two-country world, only one of the asset stocks is independent. We let this be the foreign country's asset stock. Second, we treat the home country's shadow price $(p)$ as an additional control variable. This augmented system determines the world control vector as a function of the world controlled state vector $\left[k_{t}, k_{t}^{*}, b_{t}^{*}\right]$; the world costate vector $\left[\lambda_{t}, \lambda_{t}^{*}, p_{t}^{*}\right]$; and the exogenous variables $\left[A_{t}, A_{t}^{*}\right]$. Third, we impose the equilibrium condition that $P_{t}^{B}=\widetilde{\beta} E_{t}\left(p_{t+1} / \gamma p_{t}\right)$. That is, we replace $P_{t}^{B}$ with the expression $\widetilde{\beta} E_{t}\left(p_{t+1} / p_{t}\right)$ in the accumulation equations.

This three-step procedure yields a dynamic system with that can be linearized and solved in the standard manner. Note that the new state variable- the foreign country's bond holdings - is a sufficient statistic for the current distribution of wealth. Further, the solution satisfies the transversality conditions (12) and (13). 


\section{References}

[1] Backus, D. P. Kehoe, and F. Kydland (1992) "International Real Business Cycles," Journal of Political Economy 100, 745-775.

[2] Baxter, M. (1991) "Approximating suboptimal dynamic equilibria: An Euler equation approach," Journal of Monetary Economics 27 (October 1991), 173200.

[3] Baxter, M. and M. Crucini (1992) "Explaining Saving-Investment Correlations," American Economic Review 83 (June 1993), 416-436.

[4] Baxter, M. and R. King (1991) "Productive Externalities and Cyclical Volatility,"Institute for Empirical Macroeconomics Discussion Paper \#53, Federal Reserve Bank of Minneapolis, November 1991; forthcoming, European Economic Review.

[5] Burdett, K. and R. Wright (1989) "Unemployment Insurance and Short-Time Compensation: The Effects on Layoffs, Hours per Worker, and Wages," Journal of Political Economy 97 (December), 1479-1496.

[6] Cardia, E. (1991) "The Dynamics of a Small Open Economy in Response to Monetary, Fiscal, and Productivity Shocks," Journal of Monetary Economics 28:3 (December 1991).

[7] Christiano, L. and M. Eichenbaum (1992) "Current real-business-cycle theories and aggregate labor market fluctuations," American Economic Review 82 (June 1992), 430-450.

[8] Cole, H. (1988) "Financial Structure and International Trade," International Economic Review 29:2 (May 1988) 237-259.

[9] Conze, A., J.M. Lasry, and J. Scheinkman (1990) "Borrowing constraints and international comovements," manuscript, University of Chicago, September 1990.

[10] Constantinides, G. and D. Duffie (1991) "Asset pricing with heterogeneous consumers," working paper, Stanford University.

[11] Correia, I., J. Neves and S. Rebelo (1994) "Business cycles in a small open economy," forthcoming, European Economic Review.

[12] Dotsey, M. and C.S. Mao (1992) "How well do approximation methods work?" Journal of Monetary Economics 29:25-58.

[13] Hayashi, Fumio (1982) "Tobin's marginal q and average q: A neoclassical interpretation," Econometrica vol, 213-224. 
[14] Heaton, J. and D. Lucas (1994) "The importance of investor heterogeneity and financial market imperfections for the behavior of asset prices," Carnegie Rochester Conference Series on Public Policy.

[15] Hodrick, R. and E. Prescott (1980) "Post-War U.S. Business Cycles: An Empirical Investigation," manuscript, November 1980.

[16] King, R. (1990) "Value and Capital in the Equilibrium Business Cycle Program," in Value and Capital: Fifty Years Later, L. McKenzie and S. Zamagni, eds., London: MacMillan (1990).

[17] King, R., C. Plosser and S. Rebelo (1987) "Technical Appendix to Production, Growth, and Business Cycles." manuscript, University of Rochester.

[18] (1988a) "Production, Growth, and Business Cycles I: The Basic Neoclassical Model," Journal of Monetary Economics 21, 195-232.

[19] - (1988b) "Production, Growth, and Business Cycles II: New Directions," Journal of Monetary Economics 21, 309-342.

[20] King, R. and S. Rebelo (1993) "Low frequency filtering and real business cycles," Journal of Economic Dynamics and Control 17, 207-231.

[21] Kollman, R. (1990) "Incomplete asset markets and intermational real business cycles," manuscript, University of Montreal, April 1993.

[22] Mendoza, E. (1991) "Real Business Cycles in a Small Open Economy," American Economic Review, September 1991.

[23] Mitchell, W. Business cycles: The problem and its setting, New York: National Bureau of Economic Research, 1927.

[24] Morgenstern, O. (1959) International financial transactions and business cycles, Princeton: Princeton University Press.

[25] Obstfeld, M. (1986) "Capital Mobility in the World Economy: Theory and Measurement," Carnegie-Rochester Conference Series on Public Policy 24, 55-104.

[26] Rebelo, S. (1987) "Tractable heterogeneity and near-steady-state dynamics," manuscript, Northwestern University, 1987.

[27] Reynolds, P. (1992) "International comovements in production and consumption: Theory and evidence," manuscript, University of Southern California, November 1992.

[28] Reynolds, P. (1993) "International comovements in aggregate productivity: An empirical analysis," manuscript, University of Southern California, December 1993. 
[29] Park, J.Y. (1990) "Testing for Unit Roots and Cointegration by Variable Addition," Advances in Econometrics 8, 107-133.

[30] Solow, R. (1957) "Technical Progress and the Aggregate Production Function," Review of Economic Studies 39, 312-320.

[31] Stockman, A. and L. Svensson (1987) "Capital Flows, Investment, and Exchange Rates," Journal of Monetary Economics.

[32] Taylor, J. and H. Uhlig (1990) "Solving Nonlinear Stochastic Growth Models: A Comparison of Alternative Solution Methods," Journal of Business and Economic Statistics 8, 1-18.

[33] Telmer, C.I. "Asset-pricing puzzles and incomplete markets," Journal of Finance 48 (December 1993), 1803-1832 


\section{TABLE 1}

\section{Statistical Properties of International Solow Residuals ${ }^{1}$}

\section{Panel A: Park and Choi J(p,q) Test for Unit Root}

(The null hypothesis is a unit root: the hypothesis is rejected if the test statistic is smaller than the critical value)

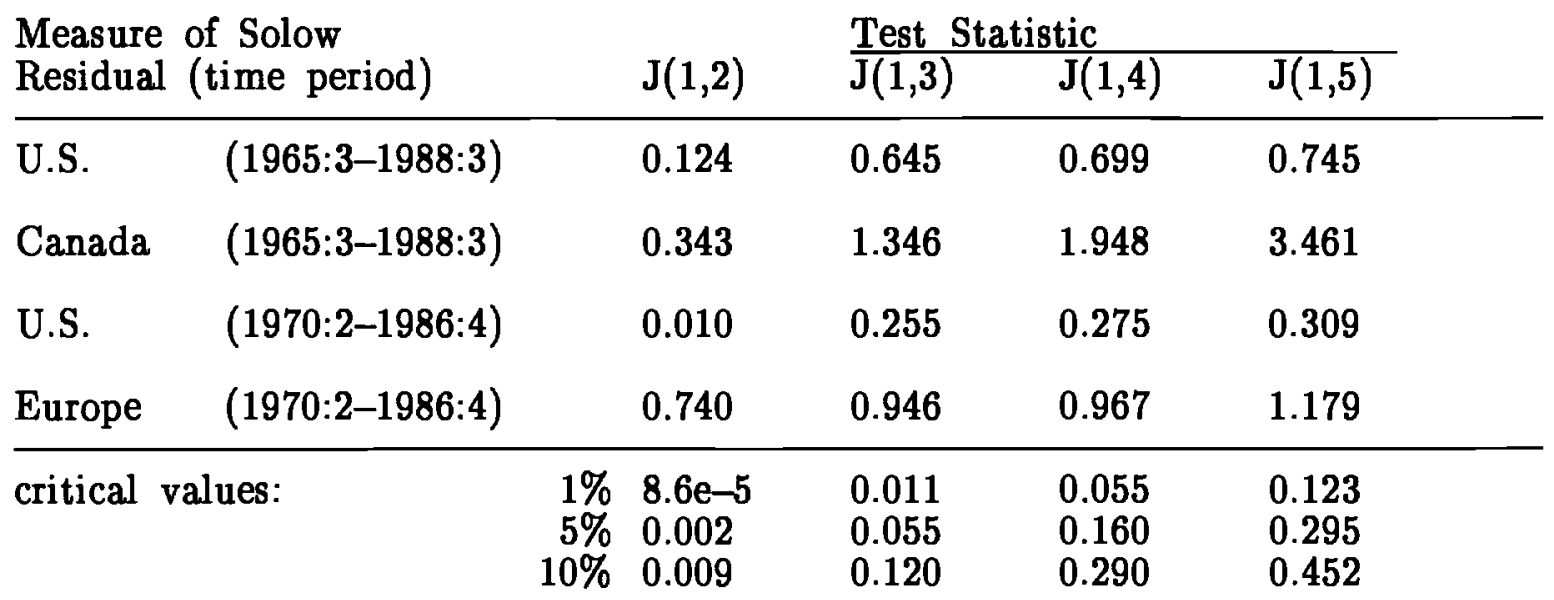

\section{Panel B: Tests for Cointegration}

We used Park's canonical cointegrating regression to estimate $\alpha_{1}$ such that $\mathrm{A}_{\mathrm{t}}-\alpha \mathrm{A}_{\mathrm{t}}^{*}=$ $\epsilon_{\mathrm{t}}$, a stationary random variable. Next, we used Park's $\mathrm{H}(\mathrm{p}, \mathrm{q})$ test for stochastic cointegration; p-values are given in the table below. In each case, the U.S. is the unstarred variable (i.e., $\alpha$ is the coefficient on Canada or Europe).

\begin{tabular}{lccllll}
\hline & & & \multicolumn{4}{c}{$\mathrm{p}$-values } \\
\cline { 5 - 7 } & $\hat{\alpha}$ & $\mathrm{se}(\hat{\alpha})$ & $\mathrm{H}(1,2)$ & $\mathrm{H}(1,3)$ & $\mathrm{H}(1,4)$ & $\mathrm{H}(1,5)$ \\
U.S. - Canada & 0.580 & 0.061 & 0.313 & 0.523 & 0.707 & 0.462 \\
U.S. - Europe & 0.603 & 0.041 & 0.046 & 0.039 & 0.082 & 0.145 \\
\hline
\end{tabular}


Table 1, cont'd.

\section{Panel C: Estimates of stochastic processes for Solow residuals}

$\Delta$ denotes the first difference of a variable, i.e., $\Delta A_{t} \equiv A_{t}-A_{t-1}$; as before the U.S. is the unstarred country. Standard errors are in parentheses.

\section{U.S.-Canada:}

$$
\begin{aligned}
\Delta \mathrm{A}_{\mathrm{t}}= & \underset{(0.001)}{0.003}+\underset{(0.117)}{0.113} \Delta \mathrm{A}_{\mathrm{t}-1}+\underset{(0.101)}{0.048} \Delta \mathrm{A}_{\mathrm{t}-1}^{*}-\underset{(0.052)}{0.074}\left(\mathrm{~A}_{\mathrm{t}-1}-\mathrm{A}_{\mathrm{t}-1}^{*}\right)+\mathrm{u}_{\mathrm{t}} \\
\Delta \mathrm{A}_{\mathrm{t}}^{*}= & \underset{(0.001)}{0.005}+\underset{(0.131)}{0.283} \Delta \mathrm{A}_{\mathrm{t}-1}+\underset{(0.112)}{0.035} \Delta \mathrm{A}_{\mathrm{t}-1}^{*}+\underset{(0.058)}{0.021}\left(\mathrm{~A}_{\left.\mathrm{t}-1-\mathrm{A}_{\mathrm{t}-1}^{*}\right)+\mathrm{u}_{\mathrm{t}}^{*}}\right. \\
& \hat{\sigma}_{\mathrm{u}}^{2}=8.38 \mathrm{e}-3 ; \quad \hat{\sigma}_{\mathrm{u}^{*}}^{2}=9.34 \mathrm{e}-3 ; \hat{\rho}\left(\mathrm{u}, \mathrm{u}^{*}\right)=0.392 .
\end{aligned}
$$

U.S.-Europe: (error-correction term omitted due to lack of cointegration)

$$
\begin{aligned}
\Delta \mathrm{A}_{\mathrm{t}}= & \underset{(0.001)}{0.002}+\underset{(0.126)}{0.003} \Delta \mathrm{A}_{\mathrm{t}-1}+\underset{(0.134)}{0.193} \Delta \mathrm{A}_{\mathrm{t}-1}^{*}+\mathrm{u}_{\mathrm{t}} \\
\Delta \mathrm{A}_{\mathrm{t}}^{*}= & \underset{(0.001)}{0.005}+\underset{(0.110)}{0.196} \Delta \mathrm{A}_{\mathrm{t}-1}-\underset{(0.117)}{0.076} \Delta \mathrm{A}_{\mathrm{t}-1}^{*}+\mathrm{u}_{\mathrm{t}}^{*} \\
& \hat{\sigma}_{\mathrm{u}}^{2}=9.07 \mathrm{e}-3 ; \quad \hat{\sigma}_{\mathrm{u}^{*}}^{2}=7.95 \mathrm{e}-3 ; \hat{\rho}\left(\mathrm{u}, \mathrm{u}^{*}\right)=0.228 .
\end{aligned}
$$

\section{Notes:}

1. All the tests reported in this table are discussed in Park [1990]. 
TABLE 2

Business Cycle Statistics for 8 OECD Countries

\begin{tabular}{lcccccc}
\hline & \multicolumn{3}{c}{$\begin{array}{c}\text { relative } \\
\text { volatility }\end{array}$} & & \multicolumn{2}{c}{$\begin{array}{c}\text { contemporaneous } \\
\text { correlation }\end{array}$} \\
\hline Country & $\sigma_{\mathrm{c}} / \sigma_{\mathrm{y}}$ & $\sigma_{\mathrm{i}} / \sigma_{\mathrm{y}}$ & $\sigma_{\mathrm{nx} / \mathrm{y}}$ & $\rho_{\mathrm{y}}$ & $\rho(\mathrm{c}, \mathrm{y})$ & $\rho(\mathrm{i}, \mathrm{y})$ \\
\hline Australia & 0.69 & 2.17 & 1.46 & 0.67 & 0.62 & 0.55 \\
Canada & 0.88 & 2.83 & 0.83 & 0.79 & 0.72 & 0.62 \\
France & 0.89 & 1.92 & 0.81 & 0.79 & 0.58 & 0.45 \\
Germany & 0.70 & 3.40 & 0.88 & 0.71 & 0.64 & 0.80 \\
Italy & 0.82 & 2.49 & 1.76 & 0.78 & 0.70 & 0.80 \\
Japan & 1.12 & 2.31 & 0.93 & 0.74 & 0.47 & 0.60 \\
Switzerland & 0.77 & 2.88 & 1.50 & 0.70 & 0.74 & 0.73 \\
U.S.A. & 0.67 & 3.00 & 0.41 & 0.84 & 0.88 & 0.90 \\
\hline
\end{tabular}

\begin{tabular}{|c|c|c|c|c|}
\hline \multirow[b]{2}{*}{ Country } & \multicolumn{2}{|c|}{$\begin{array}{c}\text { correlation with } \\
\text { same U.S. variable }\end{array}$} & \multirow{2}{*}{\multicolumn{2}{|c|}{$\begin{array}{l}\text { Additional labor market } \\
\text { statistics for the USA }\end{array}$}} \\
\hline & output & cons'n. & & \\
\hline Australia & 0.24 & 0.11 & $\sigma_{\mathrm{N}} / \sigma_{\mathrm{y}}:$ & 0.84 \\
\hline Canada & 0.77 & 0.65 & $\sigma_{\text {prod. }} / \sigma_{\mathrm{y}}:$ & 0.57 \\
\hline France & 0.50 & 0.28 & $\rho(\mathrm{N}, \mathrm{y})$ & 0.83 \\
\hline Germany & 0.44 & 0.45 & $\rho($ prod, $y):$ & 0.54 \\
\hline Italy & 0.47 & 0.23 & $\rho($ prod, $N)$ & -0.04 \\
\hline Japan & 0.42 & 0.41 & & \\
\hline Switzerland & 0.28 & 0.22 & & \\
\hline U.S.A. & 1.00 & 1.00 & & \\
\hline
\end{tabular}




\section{Notes to Table 2:}

With the exception of the U.S. labor market statistics, all statistics are taken from Baxter and Crucini [1991]. The data is from the International Financial Statistics, and is quarterly postwar data, with coverage varying by country. This is the same database used by Backus, Kehoe, and Kydland [1992] who graciously provided us with their data.

Statistics for U.S. labor markets were taken from Baxter and King [1991]; the original data source was Citibase. The data is quarterly data from 1955:1-1990:3. In this table, "N" denotes labor input (hours worked), and "prod" denotes productivity computed as output per manhour.

All data has been detrended using the Hodrick-Prescott [1980] filter. 
Table 3

\section{Trend Stationary Shocks}

(1) results for complete markets economy

(2) results for economy trading noncontingent bonds and goods only

\begin{tabular}{|c|c|c|c|c|c|c|c|c|c|c|c|}
\hline & \multicolumn{2}{|c|}{$\begin{array}{c}\text { Standard } \\
\text { deviation }\end{array}$} & \multicolumn{2}{|c|}{$\begin{array}{l}\text { Relative } \\
\text { std. dev. }\end{array}$} & \multicolumn{2}{|c|}{ Persistence } & \multicolumn{2}{|c|}{$\begin{array}{c}\text { corr } w / y, \\
\operatorname{lag} 0\end{array}$} & & \multicolumn{2}{|c|}{$\begin{array}{c}\text { Other } \\
\text { Correlations }\end{array}$} \\
\hline & (1) & (2) & (1) & (2) & (1) & (2) & (1) & (2) & & $(1)$ & (2) \\
\hline output & 2.01 & 1.99 & 1.00 & 1.00 & 0.75 & 0.76 & 1.00 & 1.00 & $y, y^{*}$ & 0.04 & 0.06 \\
\hline cons'n & 0.97 & 0.98 & 0.48 & 0.49 & 0.81 & 0.81 & 0.82 & 0.84 & $c, c^{*}$ & 0.95 & 0.92 \\
\hline invest. & 3.72 & 3.55 & 1.85 & 1.79 & 0.73 & 0.74 & 0.98 & 0.97 & $\mathrm{i}, \mathrm{i}^{*}$ & 0.02 & 0.12 \\
\hline labor & 1.07 & 1.02 & 0.53 & 0.51 & 0.73 & 0.72 & 0.91 & 0.91 & $\mathrm{~N}, \mathrm{~N}^{*}$ & -0.70 & -0.67 \\
\hline wage & 1.13 & 1.14 & 0.56 & 0.57 & 0.80 & 0.80 & 0.92 & 0.93 & $\mathrm{w}, \mathrm{w}^{*}$ & 0.75 & 0.72 \\
\hline net & 0.57 & 0.59 & 0.29 & 0.30 & 0.80 & 0.80 & 0.65 & 0.65 & $\mathrm{~s}, \mathrm{i}$ & 0.95 & 0.94 \\
\hline bonds & 0.00 & 3.22 & 0.00 & 1.62 & 0.00 & 0.98 & 0.00 & 0.23 & $w, N$ & 0.66 & 0.69 \\
\hline
\end{tabular}


Table 4

\section{Unit Root in Productivity}

(1) results for complete markets economy

(2) results for economy trading noncontingent bonds and goods only

\begin{tabular}{|c|c|c|c|c|c|c|c|c|c|c|c|}
\hline & \multicolumn{2}{|c|}{$\begin{array}{r}\text { Standard } \\
\text { deviation } \\
\end{array}$} & \multicolumn{2}{|c|}{$\begin{array}{l}\text { Relative } \\
\text { std. dev. }\end{array}$} & \multicolumn{2}{|c|}{ Persistence } & \multicolumn{2}{|c|}{$\begin{array}{c}\text { corr w/y, } \\
\operatorname{lag} 0 \\
\end{array}$} & & \multicolumn{2}{|c|}{$\begin{array}{c}\text { Other } \\
\text { Correlations }\end{array}$} \\
\hline & (1) & (2) & (1) & (2) & (1) & (2) & (1) & (2) & & (1) & (2) \\
\hline output & 2.58 & 1.59 & 1.00 & 1.00 & 0.87 & 0.82 & 1.00 & 1.00 & $\mathrm{y}, \mathrm{y}^{*}$ & -0.41 & 0.54 \\
\hline cons'n & 1.03 & 1.67 & 0.40 & 1.05 & 0.82 & 0.80 & 0.72 & 0.85 & $\mathrm{c}, \mathrm{c}^{*}$ & 0.89 & -0.28 \\
\hline invest & 11.84 & 4.74 & 4.60 & 2.98 & 0.77 & 0.78 & 0.71 & 0.74 & $\mathrm{i}, \mathrm{i}^{*}$ & -0.92 & -0.50 \\
\hline labor & 1.58 & 0.71 & 0.61 & 0.45 & 0.89 & 0.78 & 0.93 & 0.19 & $\mathrm{~N}, \mathrm{~N}^{*}$ & -0.91 & -0.56 \\
\hline wage & 1.25 & 1.62 & 0.48 & 1.02 & 0.83 & 0.80 & 0.89 & 0.90 & $\mathrm{w}, \mathrm{w}^{*}$ & 0.50 & -0.11 \\
\hline net & 2.39 & 1.61 & 0.93 & 1.01 & 0.81 & 0.77 & -0.18 & -0.28 & $\mathrm{~s}, \mathrm{i}$ & 0.74 & 0.04 \\
\hline bonds & 0.00 & 8.18 & 0.00 & 5.13 & 0.00 & 0.98 & 0.00 & 0.35 & $\mathrm{w}, \mathrm{N}$ & 0.66 & -0.25 \\
\hline
\end{tabular}




\section{FIGURE 1}

Random walk productivity without spillovers:

Quantity responses to productivity shock in home country
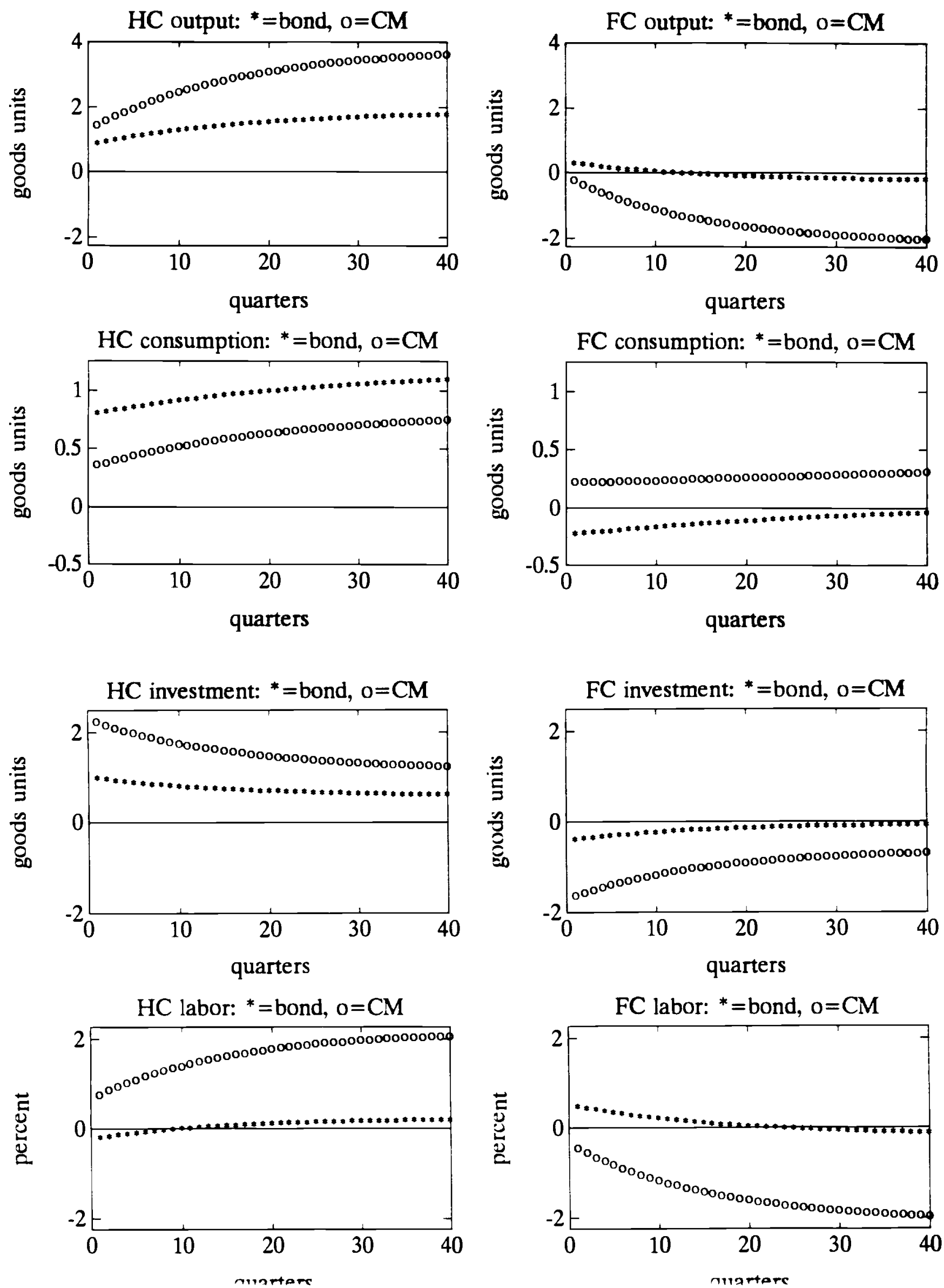


\section{FIGURE 2}

Random walk productivity without spillovers:

Price and interest rate responses to productivity shock in home country
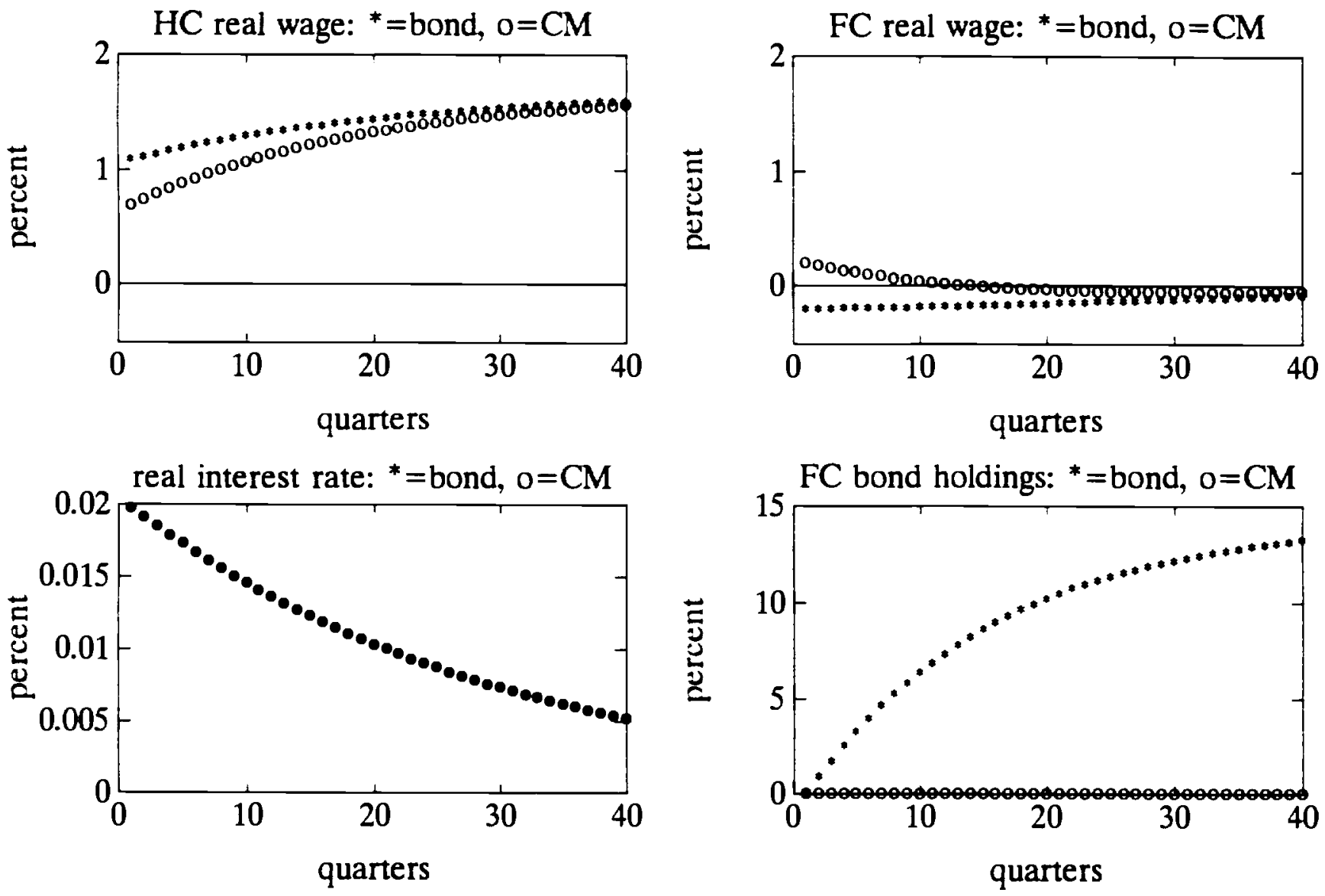
FIGURE 3-A

Random walk productivity without spillovers:

Hicksian decomposition of consumption response
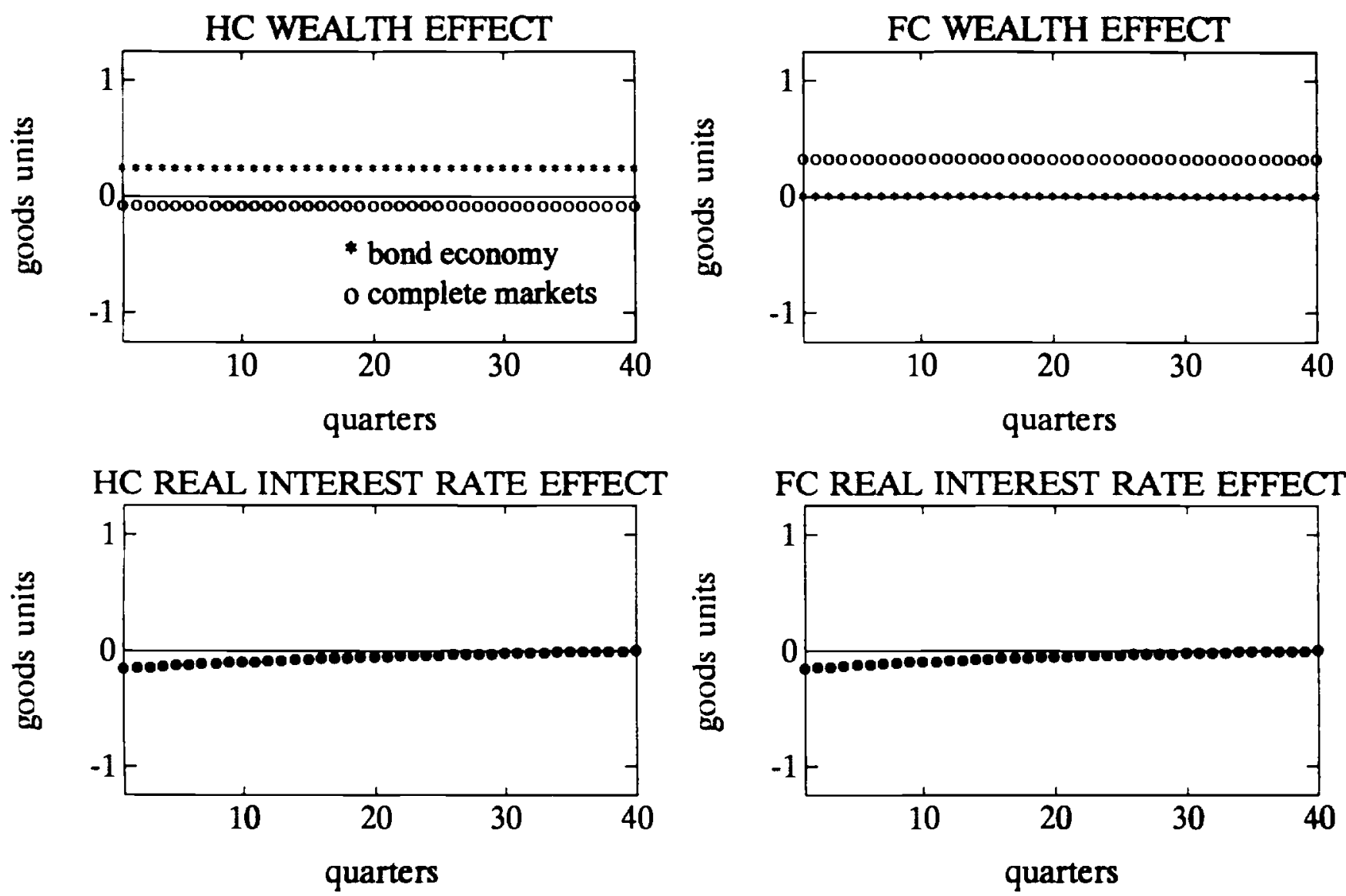

HC WAGE EFFECT
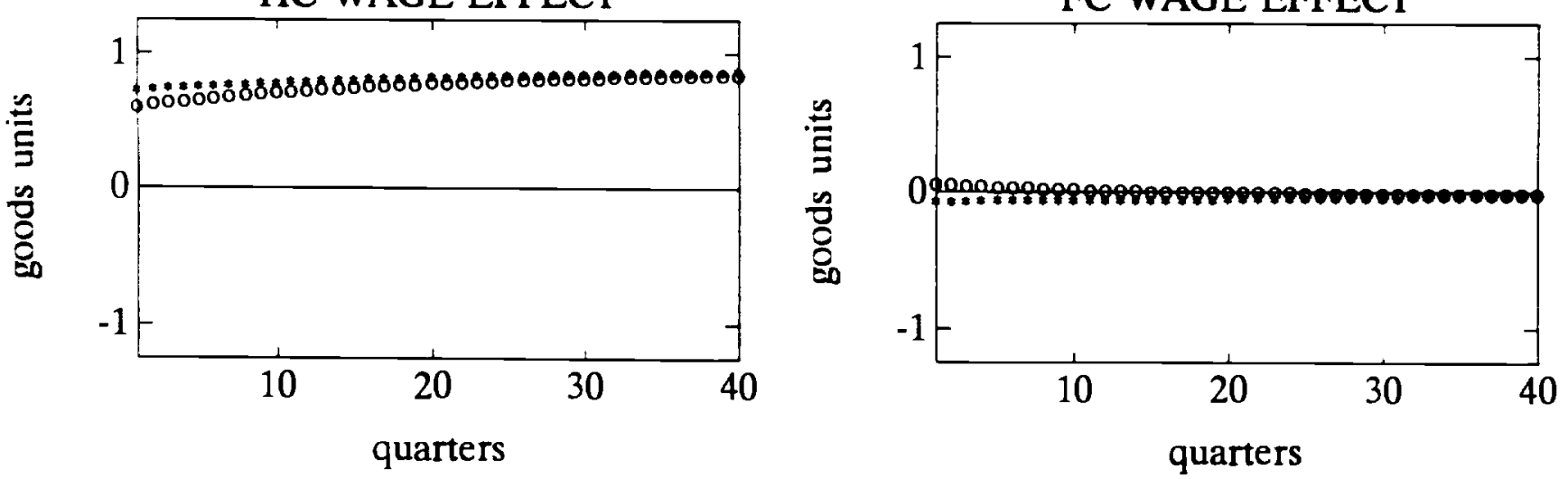

HC TOTAL CONSUMPTION EFFECT

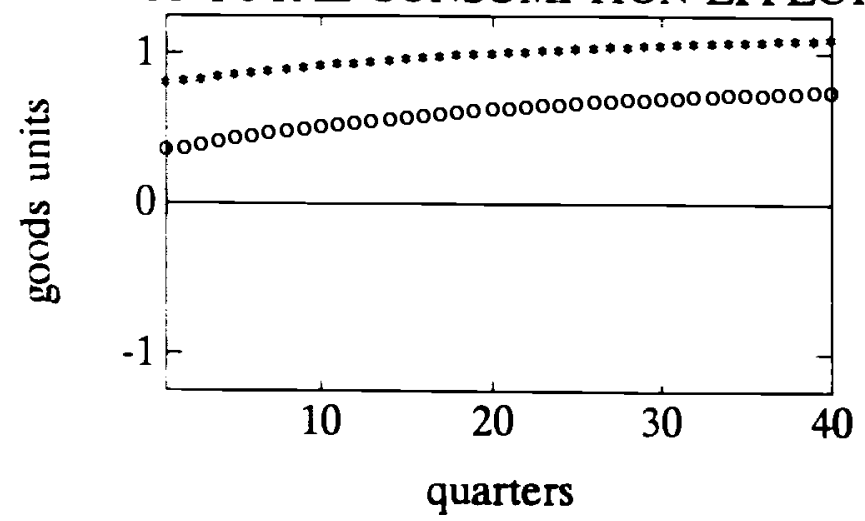

FC TOTAL CONSUMPTION EFFECT

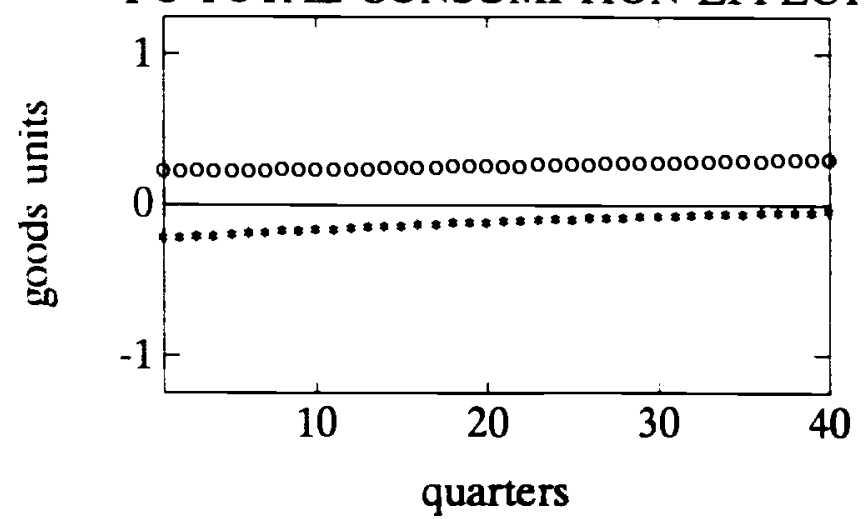


FIGURE 3-B

Random walk productivity without spillovers:

Hicksian decomposition of labor response
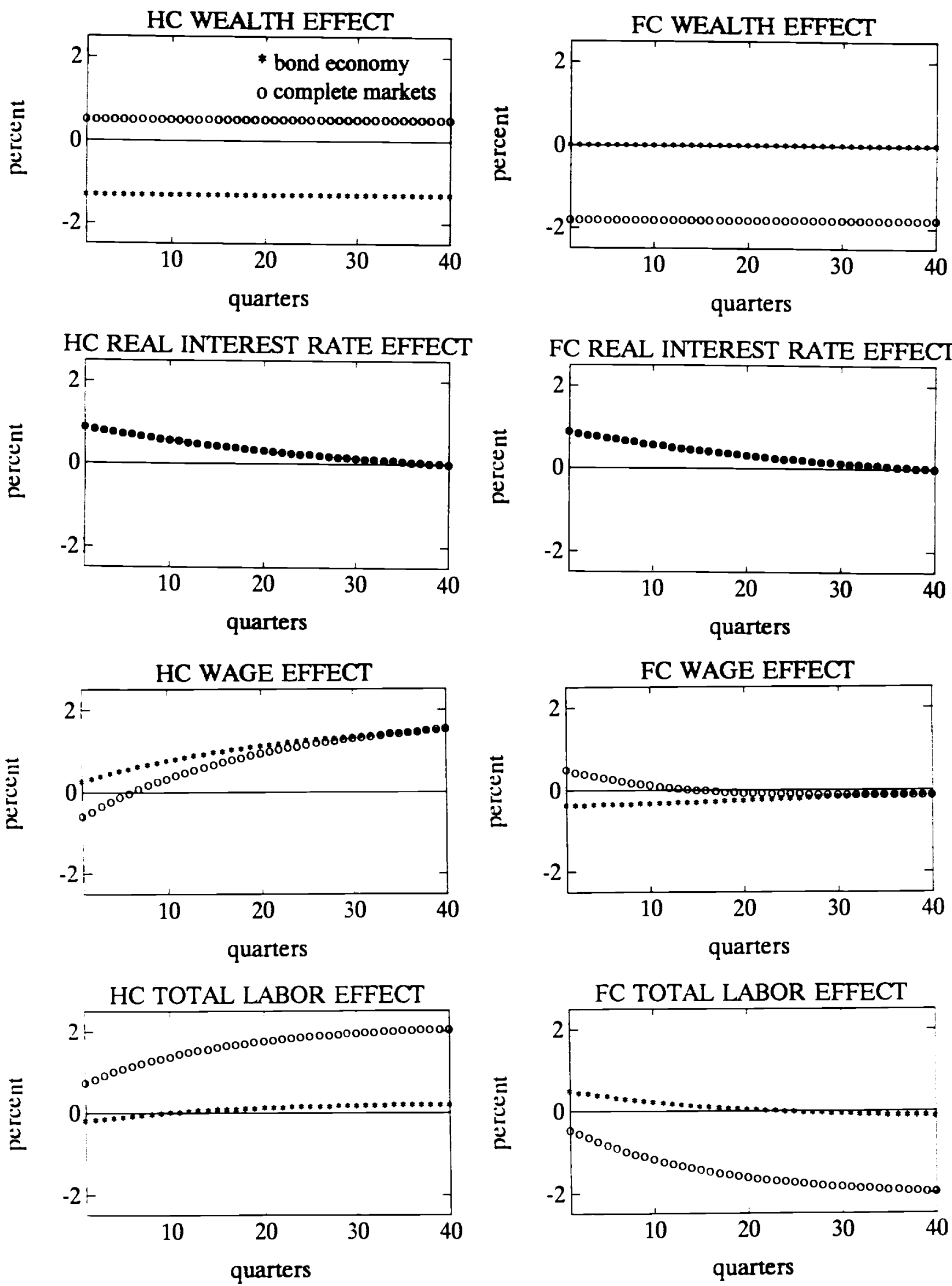


\section{FIGURE 4}

Trend-stationary productivity with spillovers:

Quantity responses to productivity shock in home country
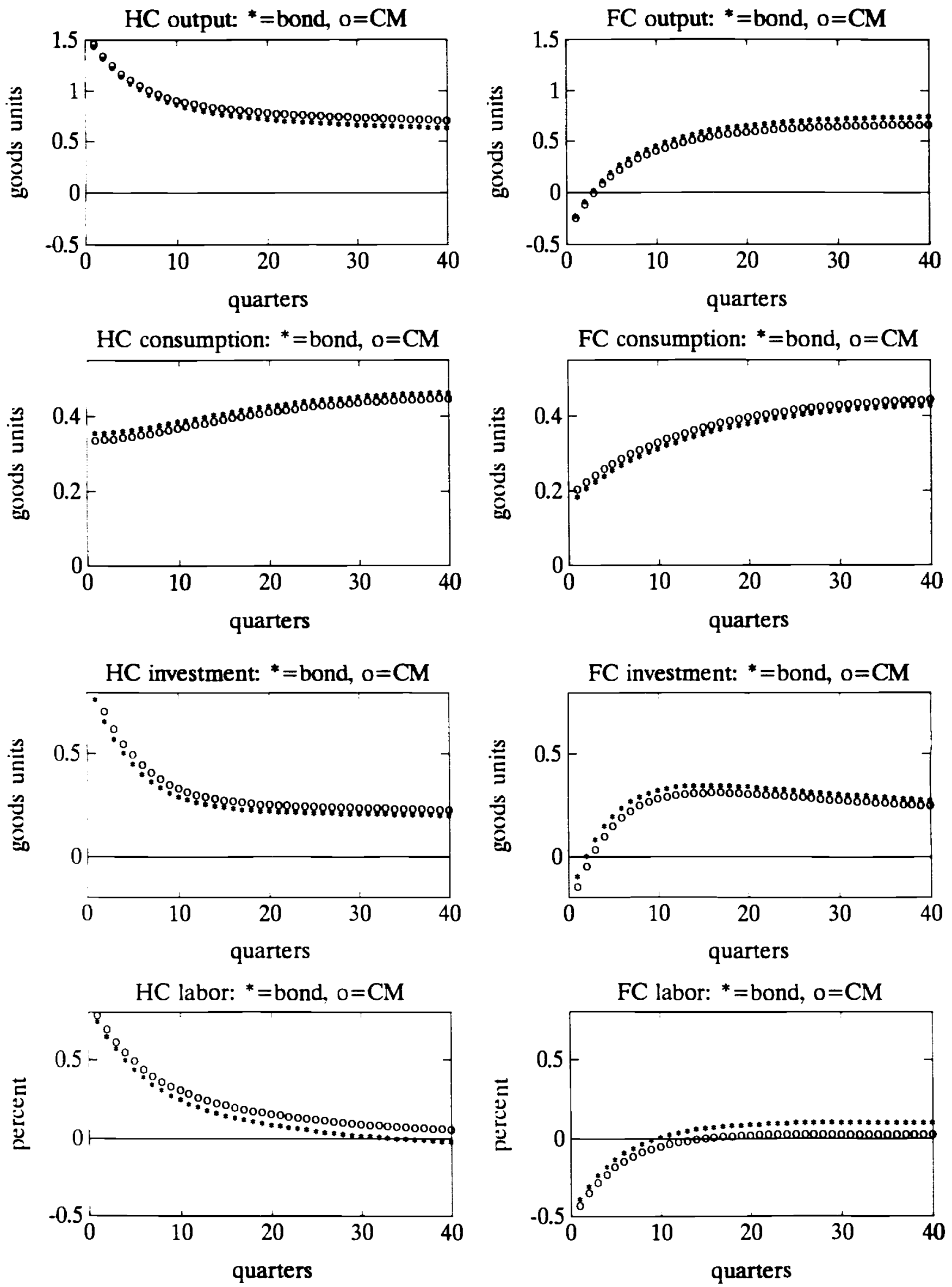


\section{FIGURE 5}

Trend-stationary productivity with spillovers:

Price and interest rate responses to productivity shock in home country
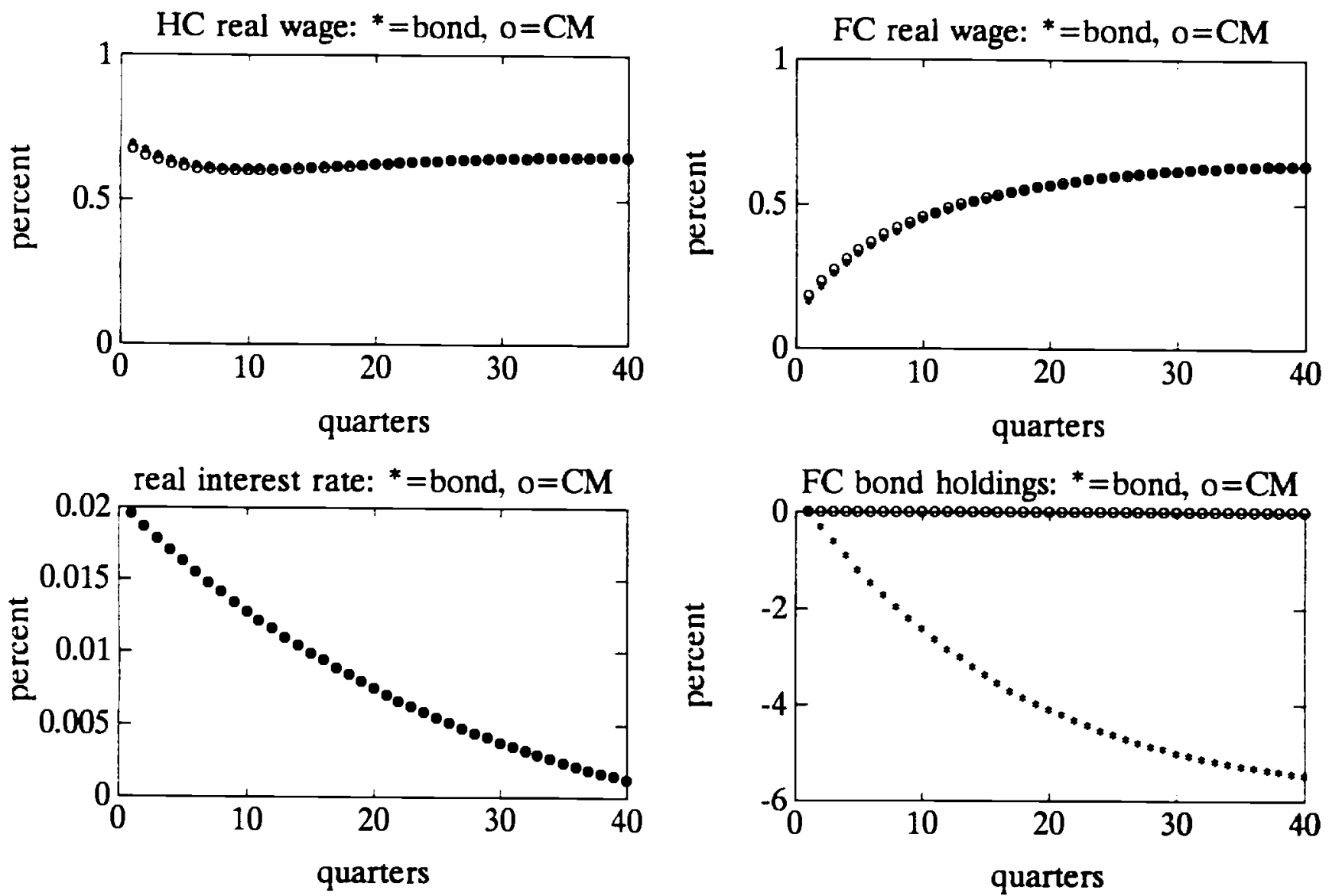
FIGURE 6-A

Trend-stationary productivity with spillovers:

Hicksian decomposition of consumption response
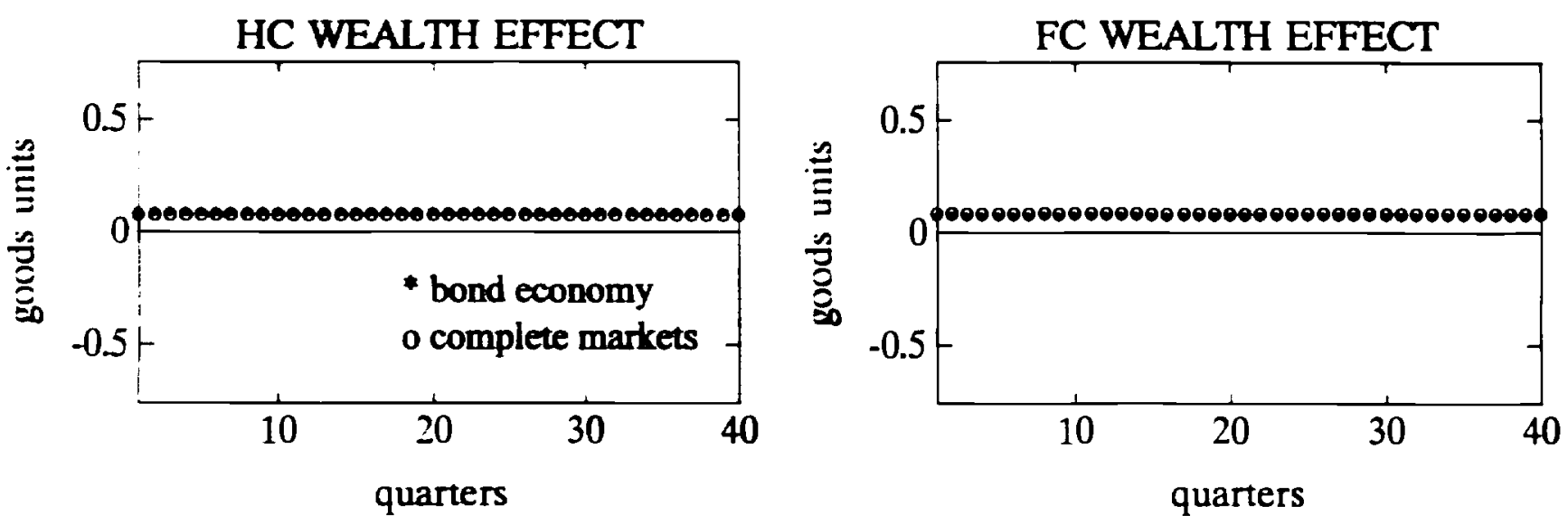

HC REAL INTEREST RATE EFFECT
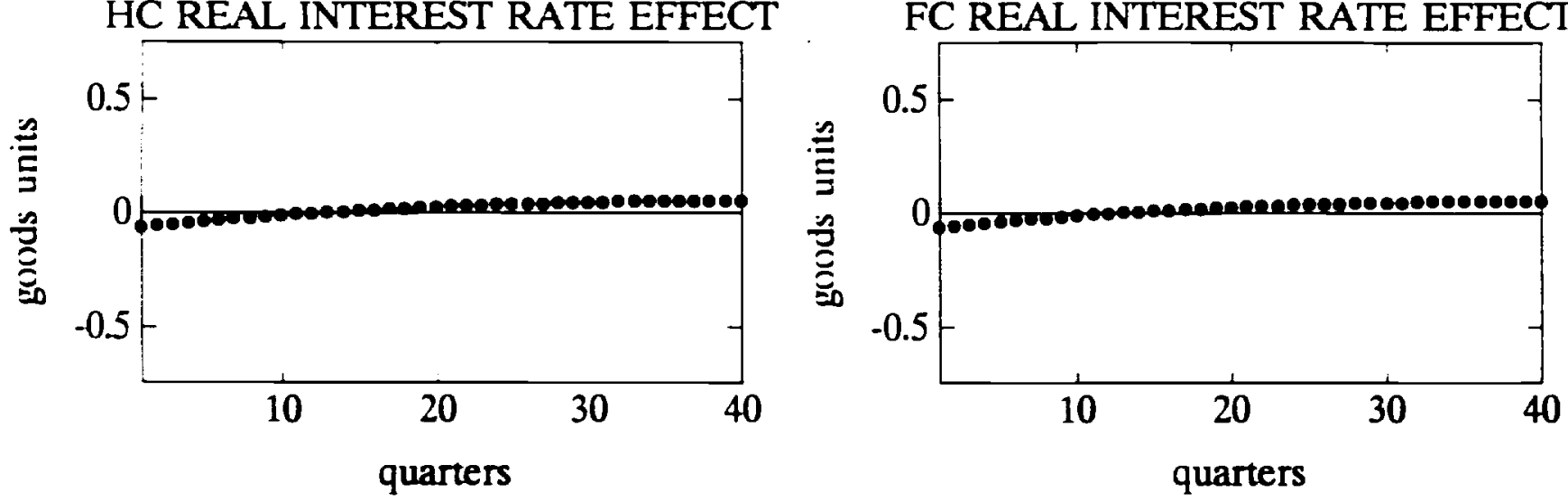

HC WAGE EFFECT
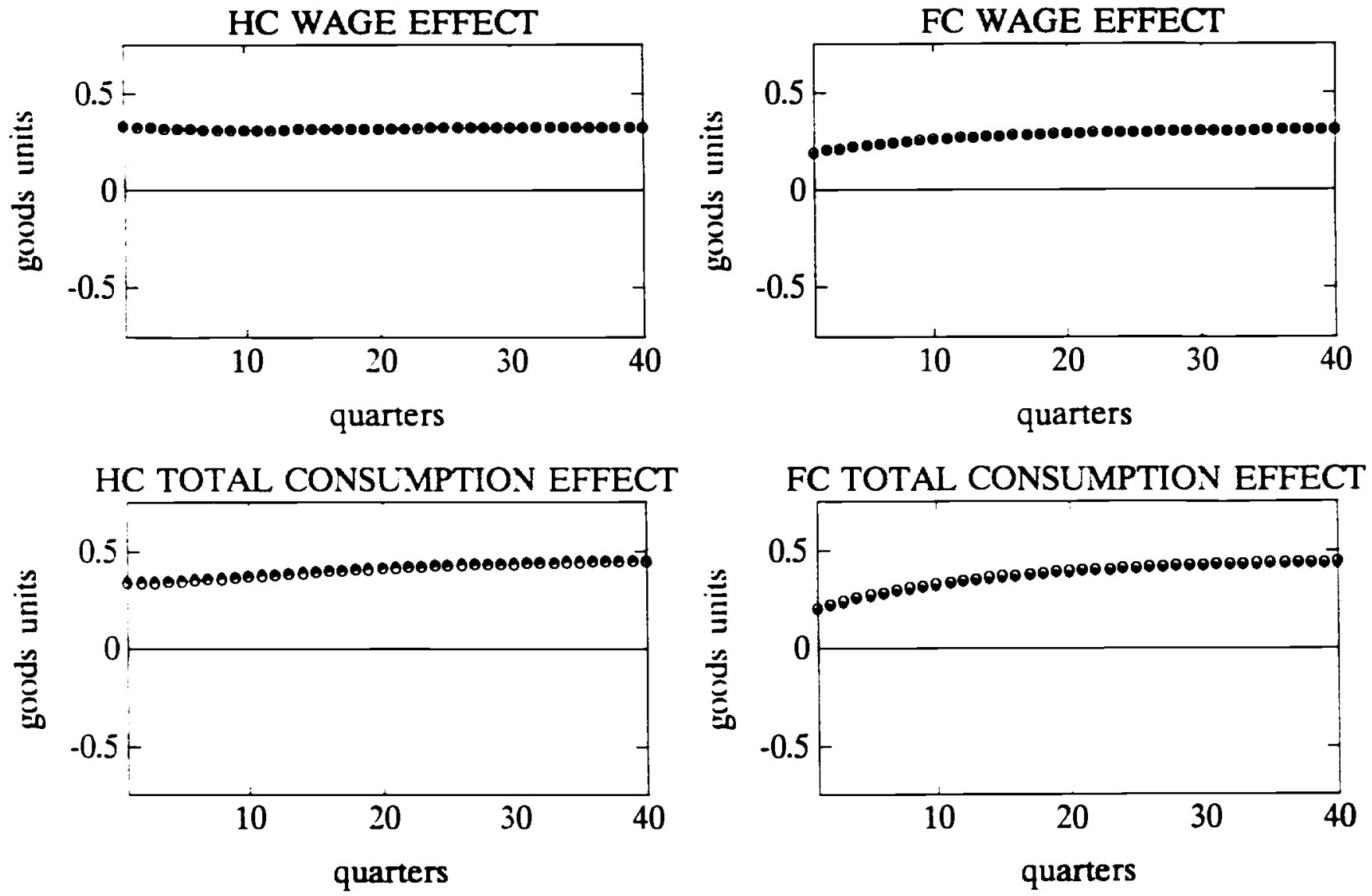
FIGURE 6-B

Trend-stationary productivity with spillovers:

Hicksian decomposition of labor response
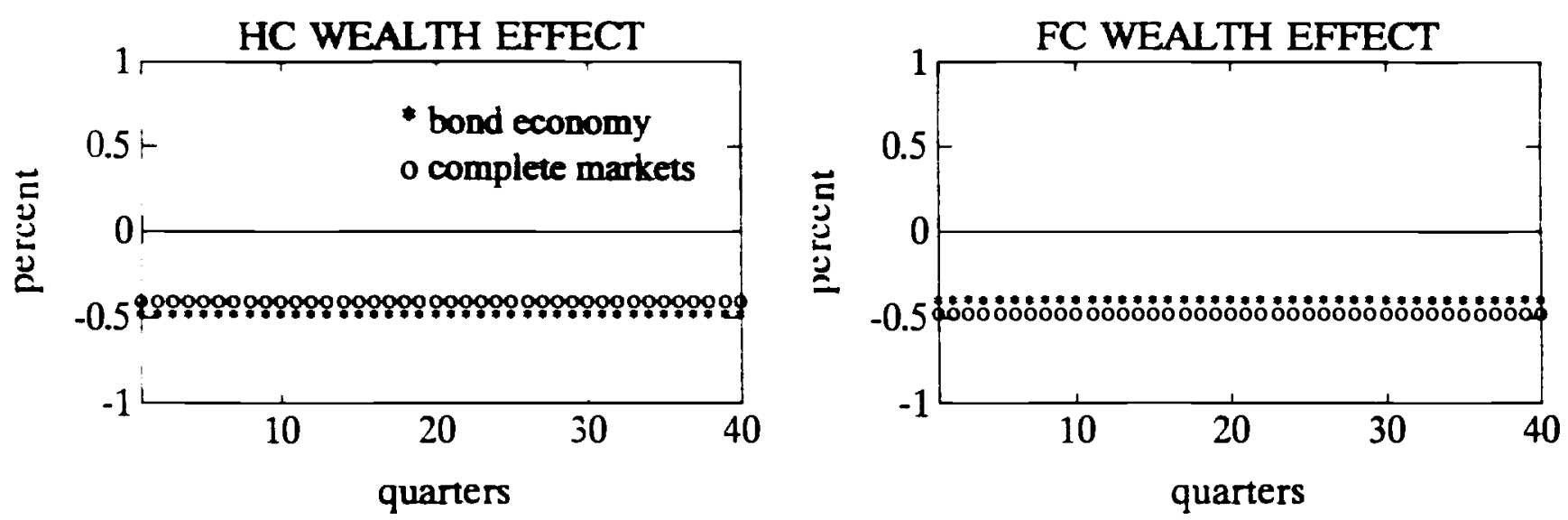

HC REAL INTEREST RATE EFFECT
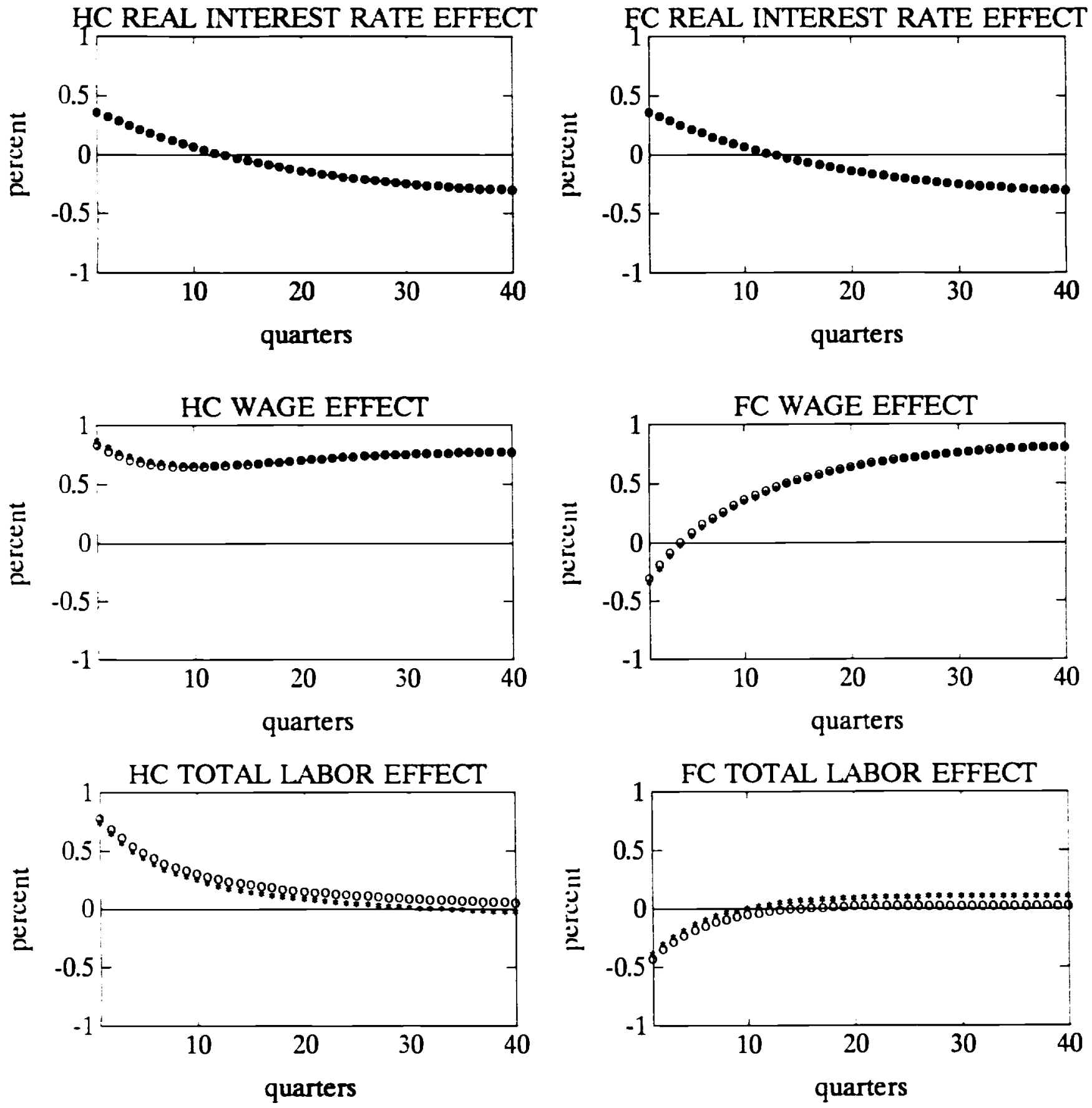